\title{
PROGRESSIVE COLLAPSE RESISTANCE OF STEEL FRAMED BUILDINGS UNDER EXTREME EVENTS
}

\author{
Guo-Qiang Li ${ }^{1}$, Jing-Zhou Zhang ${ }^{2}$, Liu-Lian Li ${ }^{3}$, Bin-Hui Jiang ${ }^{4}$, Tao-Chun Yang ${ }^{5}$ and Jian Jiang 6 ,* \\ ${ }^{1}$ State Key Laboratory for Disaster Reduction in Civil Engineering, Tongji University, 1239 Siping Road, Shanghai 200092, China \\ ${ }^{2}$ College of Civil Engineering, Tongji University, 1239 Siping Road, Shanghai 200092, China \\ ${ }^{3}$ The First Construction Engineering Company LTD. of China Construction Second Engineering Bureau, No. 9 Kechuangsi Street, Beijing 100176, China \\ ${ }^{4}$ School of Civil Engineering, Central South University, 68 South Shaoshan Road, Changsha 410075, China \\ School of Civil Engineering and Architecture, University of Jinan, Jinan 250022, China; \\ ${ }^{6}$ Jiangsu Key Laboratory of Environmental Impact and Structural Safety in Engineering, China University of Mining and Technology, Xuzhou 221116, China. \\ * (Corresponding Author.E-mail: jian.jiang@cumt.edu.cn)
}

\section{A B S T RA C T}

This paper presents experimental and theoretical investigations on progressive collapse behavior of steel framed structures subjected to an extreme load such as fire, blast and impact. A new capacity-based index is proposed to quantify robustness of structures. An energy-based theoretical model is also proposed to quantify the effect of concrete slabs on collapse resistance of structures. The experimental results show that the dynamic amplification factors of frames subject to impact or blast are much less than the conventional value of 2.0. The collapse process of frames in fire can be either static or dynamic depending on the restraint conditions and load levels. It is necessary to account for the failure time and residual strength of blast-exposed columns for assessing the collapse resistance of structures subject to explosion. Two collapse modes of steel frames under blast or impact are found: connection-induced collapse mode and column-induced collapse mode. In case of fire, a frame may collapse due to either column buckling or pulling-in effect of beams. The energy dissipation from elongation of slab reinforcement and additional resultant moment greatly contribute to the collapse resistance of structures.
A R T I C L E H I S T O R Y

$\begin{array}{ll}\text { Received: } & \text { 29 September } 2020 \\ \text { Revised: } & \text { 13 March } 2021 \\ \text { Accepted: } & \text { 13 March } 2021\end{array}$

\section{K E Y W O R D S}

Progressive collapse;

Steel framed building;

Blast;

Impact;

Fire

Experimental study

Copyright $\odot 2021$ by The Hong Kong Institute of Steel Construction. All rights reserved.

\section{Introduction}

Design and research on progressive collapse of building structures have developed for more than 50 years since the collapse of Ronan Point apartment in London in 1968 (Fig. 1a) [1]. The term "progressive collapse" is defined as "the spread of an initial local failure from element to element, eventually resulting in the collapse of an entire structure or a disproportionately large part of it" [2]. The requirement for preventing progressive collapse of structures was first specified in the UK design code [3], by providing a categorization of building types/occupancies to design buildings to sustain an extent of localized failure under extreme loads without progressive collapse. Similar design approaches were given in Eurocodes [4]. The collapse of Murrah federal building in 1995 (Fig. 1b) and especially that of World Trade Center towers in 2001 (Fig. 1c) [5] under terrorist attack have significantly advanced the development of U.S. codes for mitigating progressive collapse of buildings $[2,6,7]$. Afterwards there have been growing interests in understanding the progressive collapse behavior of high-rise buildings [8].

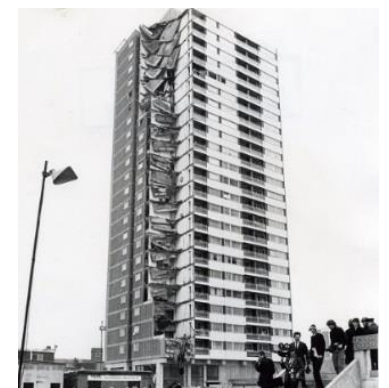

(a) Ronan Point apartment

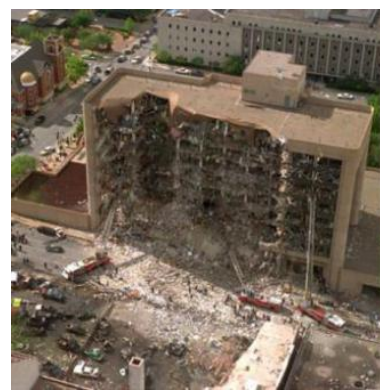

(b) Murrah federal building

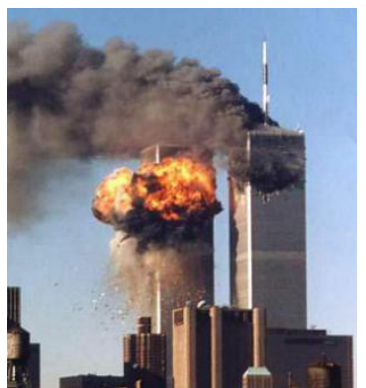

(c) World Trade Center

Fig. 1 Events of progressive collapse of buildings under extreme loading conditions

There is numerous research on the progressive collapse resistance[9] of structures under extreme loading conditions, such as blast, impact, and fire. In the case of blast or impact, the local failure is generally simulated by immediately removing columns, and the resistance of the remains are assessed to ensure alternative load-transfer paths to bridge over the missing columns. Numerous quasi-static experiments have been conducted [10-13]. Yang and Tan [10] investigated the behavior of steel beam-column connections by removing a column at center. Lew et al. [11] studied the collapse performance of frame assemblies with two kinds of moment resisting connections. Tsitos et al. [12] evaluated the applicability of design methods in earthquake engineering to progressive collapse design of steel structures by testing scaled steel frames. Xie and Shu [13] carried out experiments on three-dimensional steel frames to study the variation of internal forces due to removal of a column. The sudden removal of a column may cause dynamic effect on the behavior of structures, which cannot be accurately represented by these quasistatic tests. Many attempts have thus been made to simulate the induced dynamic effect in the process of column removal and collapse [14-19]. Xie [14] simulated the failure of the middle column by using a cylinder, and tests on three planar frames were conducted. Chen et al. [15] used a chain block to suddenly remove a perimeter column in the test on a full-scale steel frame. The influence of concrete slabs on its collapse resistance was studied. Xiao et al. $[16,17]$ simulated the sudden column removal by dislodging concrete blocks inserted in the middle of a column. The load transfer path and failure mechanism of a scaled concrete frame under column removals were investigated. However, in these dynamic tests, the duration of column removal time was not short enough where the dynamic effect induced on the damaged structure was not well represented. For most of numerical studies reported in the literature on the progressive collapse of structures due to blast or impact [20-22], there has been a general lack of validation against experimental data.

The alternate path method assumes that the column is removed immediately regardless of the magnitude and duration of blast loads. In practice, although the duration of explosion on structural members is very 
short (in millisecond), the duration of response of the member under explosion to failure may be longer depending on material properties and geometry dimensions. It is unreasonable to neglect the failure process of members in all cases. Furthermore, the damaged components may have some residual bearing capacity. The failure time and residual capacity of the damaged members will affect the resistance of a structure against progressive collapse. One objective of this paper is to study these issues.

In the case of fire, the failure of steel members and slab in the fire compartment is deemed as local failure for progressive collapse, which cannot be simulated by simply removing these heated components [23]. This is firstly because that the fire duration (in hour) is much longer than blast (in millisecond). The structural fire behavior is thus a quasi-static process before the failure of the heated members. Secondly, when a structure collapses in fire (i.e. collapse time) is one key factor in addition to whether and how it collapses. This collapse time is dependent on the failure process of heated members which interacts with surrounding members at ambient temperatures. Previous studies focus on figuring out collapse mechanisms of structures [24-42]. It has been found that the progressive collapse will be triggered by the failure of the heated columns, followed by lateral drift and failure of adjacent cool columns, respectively. The catenary action in the heated beams and tensile membrane action in the heated slabs may play an important role in resisting the collapse of structures. The collapse modes are significantly affected by load ratio, strength of beams relative to columns, slab, connection, and fire scenario. A high load ratio will cause a global downward collapse due to failure of all columns on one floor [27-29]. A relative strong beam may also result in a global downward collapse due to a more uniform load redistribution in the columns [27]. A heated beam may have a pulling-out effect on columns at low temperatures[30], and pulling-in effect at high temperatures [30]. The tensile membreane action from slabs and increasing reinforcement in the slab may facilitate the load transfer between columns [32]. A fire along edge bay is more prone to cause collapse than a central-bay fire [34, 35]. A thermo-mechanical model of composite slabs was proposed by using reduced-order shell elements [36,37], and the membrane action mechanism and fire resistance of composite slabs were investigated $[39,40]$. Recently, there is a growing concern to investigate the potential collapse of buildings in the cooling phase of a fire [32, $38,41]$ and subject to a travelling fire [43]. However, the above conclusions are drawn based on numerical results rather than experimental results. The existing experimental studies are stopped at a relatively small level of displacements (without collapse) due to the limited laboratory conditions or safety concerns. There is still lacking of non-standard fire tests on real-scale structures $[44,45]$. Another important issue is the mitigation measures against fire-induced collapse. It has been found that it is feasible to employ bracing systems and fire protections to mitigate or prevent structural collapse [46]. Therefore, it is essential to conduct fire tests designed with collapse as the ultimate limit state to verify the concluded collapse mode and to validate the numerical models.

Analytical studies have been conducted to quantify the robustness of structures, which are generally divided into structural attributes-based measures $[8,47,48]$ and structural behavior-based measures [49-55]. The former involves the demand-capacity ratio or ductility of connections, while the latter concerns load-bearing capacity, redundancy, key displacement, etc. However, there is still a lack of generalized methodologies for quantify the collapse resistance of realistic structures [23,56,57]. Most existing robustness indexes do not fully account for the influence of structural characteristics, dynamic effect and local damage. Moreover, most robustness quantifications are based on elastic analyses by excluding plastic internal force redistribution in the structure.

This paper presents experimental, numerical and analytical investigations on the progressive collapse behavior of steel framed buildings subject to impact, blast, and fire, respectively. Experiments were conducted on steel frames to study its progressive collapse resistance under impact loads, where an instantaneous knock-out scheme was used to simulate the removal of columns. A new capacity-based index was proposed to quantify the robustness of steel framed buildings. The blast-induced collapse behavior of structures was investigated, where the effect of failure time and residual strength of the blast-exposed column on the collapse resistance was studied. Fire tests on steel frames were carried out to study the collapse behavior of structures exposed to localized fires. Parametric studies were conducted to investigate the influence of dynamic effect, load ratio, beam section, fire scenario on the collapse resistance. An energy-based theoretical model was also proposed to quantify the effect of reinforced concrete slab on the collapse resistance of structures.

\section{Collapse behavior of buildings subject to impact}

\subsection{Experimental study}

Experiments were conducted on three planar steel frames with two storeys and four bays (scale ratio of 1:3) by removing a middle column on the ground floor, as illustrated in Fig. 2 [62]. The out-of-plane displacements of the frame were restrained. The dimensions of the test frames and structural components are listed in Table 1 . The beam and column members were made of H-type sections, where, for example, $\mathrm{H} 80 \times 50 \times 3 \times 4$ represents a $\mathrm{H}$-section with a depth of $80 \mathrm{~mm}$, flange width of $50 \mathrm{~mm}$, web thickness of $3 \mathrm{~mm}$ and flange thickness of $4 \mathrm{~mm}$, respectively. The case FRAME1 is to study the behaviour of the critical beam-column region with fully welded connections under a removal of a middle column. While FRAME2 and FRAME3 focused on the effect of columns on the collapse resistance of the frames where the beam-to-column connections were further strengthened by stiffeners to avoid connection failure. Weight baskets were attached to the beams to simulate the mechanical gravity loads (Fig. 2b). This is to avoid the detaching and slipping of the loading system from the specimen at large displacements. Each basket in the middle two bays and side bay had a weight of about $7.2 \mathrm{kN}$ and $4 \mathrm{kN}$, respectively.

In this study, a sudden removal of the target column was achieved by a specially designed mechanism with a pendulum hammer, as illustrated in Fig. $2 \mathrm{~b}$. This is to satisfy the requirement that the removal period should be no more than $1 / 10$ of the period of the dominant response mode [7,8]. Fig. 3 shows the details of the mechanism made up by a three-hinged strut. A brittle locking rod made of glass was first inserted in the column to keep the column straight and maintain its function. A pendulum hammer was released from a designated position to strike the column and break the glass rod, which triggered the hinge mechanism and thus removal the column (Fig. 3b). The experimental results showed that the column removal duration was around $0.02 \mathrm{~s}$, compared to $0.5 \mathrm{~s}$ for the natural period of the frame.

The deformed shapes of the frame specimens after the column removal is shown in Fig. 4. The strong beam-weak column frame FRAME2 failed as the columns failed in bending and compression, whereas FRAME1 and 3 exhibited large permanent deformations. The displacement-time curves of the three steel frame specimens at the column-removal location are shown in Fig. 5. The measured maximum dynamic deflections were $252 \mathrm{~mm}, 454 \mathrm{~mm}$ and $249 \mathrm{~mm}$ for FRAME1-3, respectively. The corresponding permanent deflections were $228 \mathrm{~mm}, 443 \mathrm{~mm}$ and $225 \mathrm{~mm}$, respectively. The experimental results showed that strong connections can effectively enhance collapse resistance of steel frames. A frame with strong beams and weak columns was prone to collapse due to failure of the columns adjacent to the removed column The catenary action of beams facilitated the dynamic load transfer from the removed column to its surrounding columns.

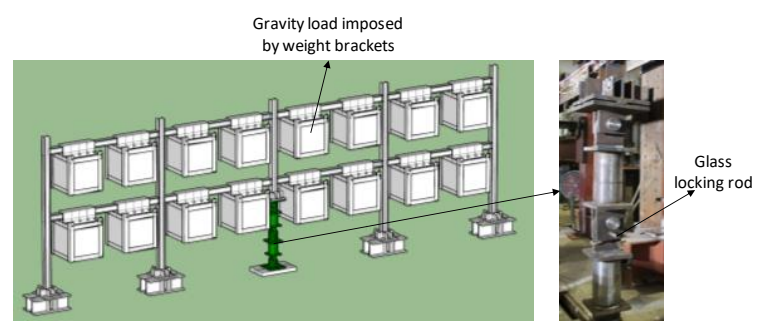

(b) gravity loading and column removal

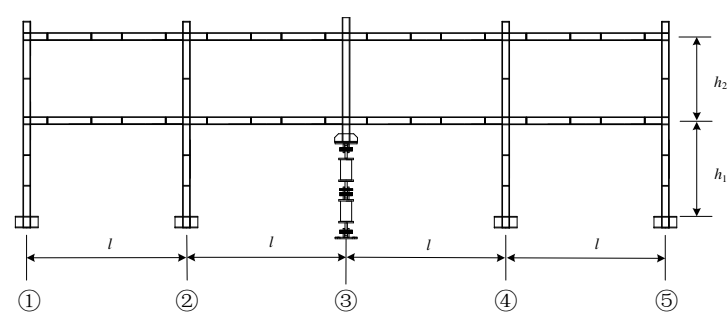

(a) frame dimension

Fig. 2 Schematic of the tested steel frame under impact 


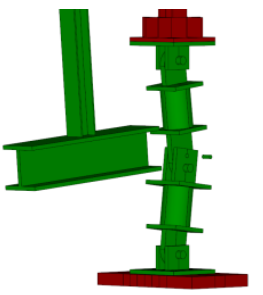

(a) break of the glass rod

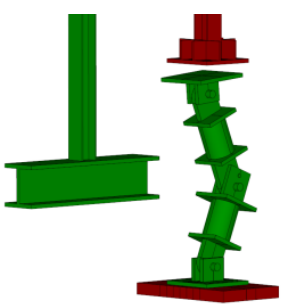

(b) formation of hinge mechanism

Fig. 3 Schematic of the column-removal mechanism

Table 1

Dimensions of the steel frame specimens

\begin{tabular}{|c|c|c|c|c|c|}
\hline \multirow[b]{2}{*}{ Specimen } & \multirow[b]{2}{*}{$\begin{array}{l}\text { Beam section } \\
(\mathrm{mm})\end{array}$} & \multirow[b]{2}{*}{$\begin{array}{l}\text { Column section } \\
\qquad(\mathrm{mm})\end{array}$} & \multicolumn{2}{|c|}{ Story height } & \multirow[b]{2}{*}{$\begin{array}{c}\text { Span length } l \\
(\mathrm{~mm})\end{array}$} \\
\hline & & & $\begin{array}{c}h_{1} \\
(\mathrm{~mm})\end{array}$ & $\begin{array}{c}h_{2} \\
(\mathrm{~mm})\end{array}$ & \\
\hline FRAME1 & $\begin{array}{l}\text { Middle bay: } \mathrm{H} 54 \times 50 \times 4 \times 4 \\
\text { Side bay: } \mathrm{H} 80 \times 50 \times 3 \times 4\end{array}$ & $\mathrm{H} 100 \times 100 \times 6 \times 8$ & 1227 & 1054 & 2100 \\
\hline FRAME2 & $\mathrm{H} 54 \times 50 \times 4 \times 4$ & H $54 \times 50 \times 4 \times 4$ & 1227 & 1054 & 2054 \\
\hline FRAME3 & $\mathrm{H} 54 \times 50 \times 4 \times 4$ & $\mathrm{H} 100 \times 100 \times 6 \times 8$ & 1227 & 1054 & 2100 \\
\hline
\end{tabular}

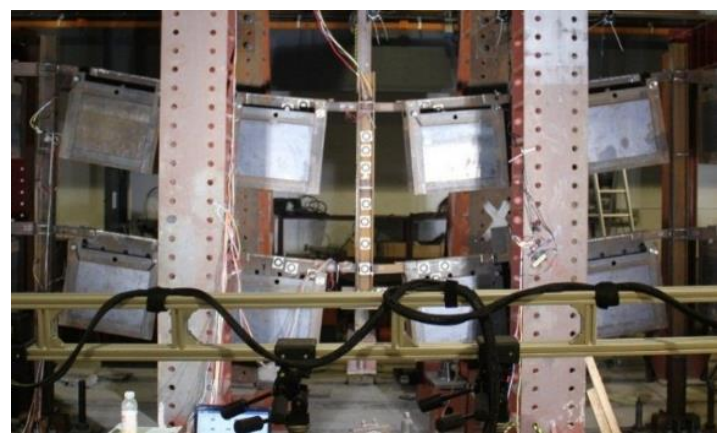

Fig. 4 Deformation of the frame specimen (FRAME1)

\subsection{Theoretical study}

\subsubsection{Concept of new robustness index}

The resistance of a structure against progressive collapse under a local failure is defined as "robustness". Structural robustness is the ability of the structure to redistribute the loads sustained by the failed members, and to remain stable after subjecting to local failure [59]. A capacity-based robustness index was proposed in Eq. (1) by comparing the imposed load on the original intact structure (Fig. 6a) and the residual capacity of the damaged structure (Fig. 6b) [60]:

$I_{r o b}=\frac{\left(q_{2 m}-\gamma q_{1 m}\right)}{q_{2 m}}=\frac{\left(q_{2 d m}-q_{1 m}\right)}{q_{2 d m}}$

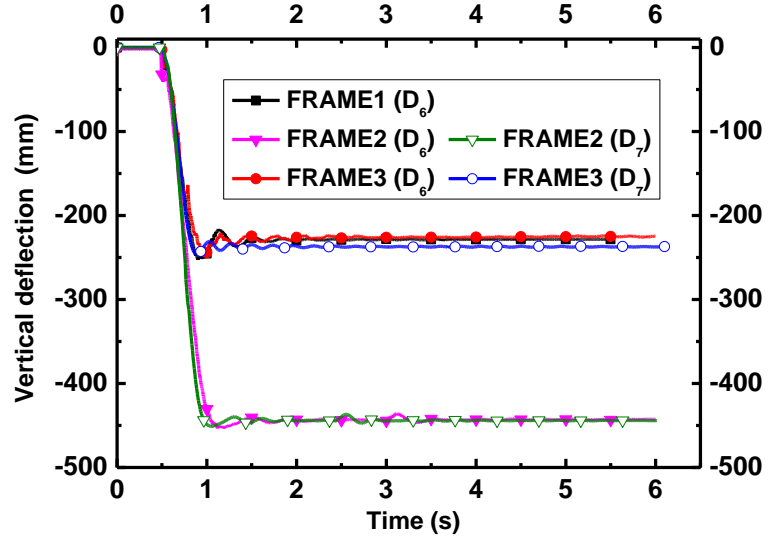

Fig. 5 Time histories of vertical deflection at the top of the removed column

where $q_{1 \mathrm{~m}}, q_{1 \mathrm{~s}}$ is the load imposed in the middle and side bays of the intact structure (Fig. 6a), respectively; $q_{2 \mathrm{~m}}, q_{2 \mathrm{~s}}$ is the static ultimate load in the middle and side bays of the damaged structure until failure (Fig. 6b), respectively; $\gamma$ is a dynamic amplification factor; $q_{2 \mathrm{dm}}$ is the dynamic critical load in the middle bays of the damaged structure until failure, which can be determined by $q_{2 d m}=q_{2 \mathrm{~m}} / \gamma$.

The proposed robustness index in Eq. (1) can explicitly account for the dynamic effect and redistribution of plastic resistance forces. If $I_{\mathrm{rob}} \leq 0$, the ultimate load of a damaged structure is less than the imposed load on the intact structure, leading to collapse of the frame lacking of necessary robustness. If $I_{\text {rob }}>0$, the frame is robust and may not collapse. The closer the $I_{\text {rob }}$ to 1 , the larger the ultimate load than the initial load imposed on the frame, and the better the robustness of the frame.
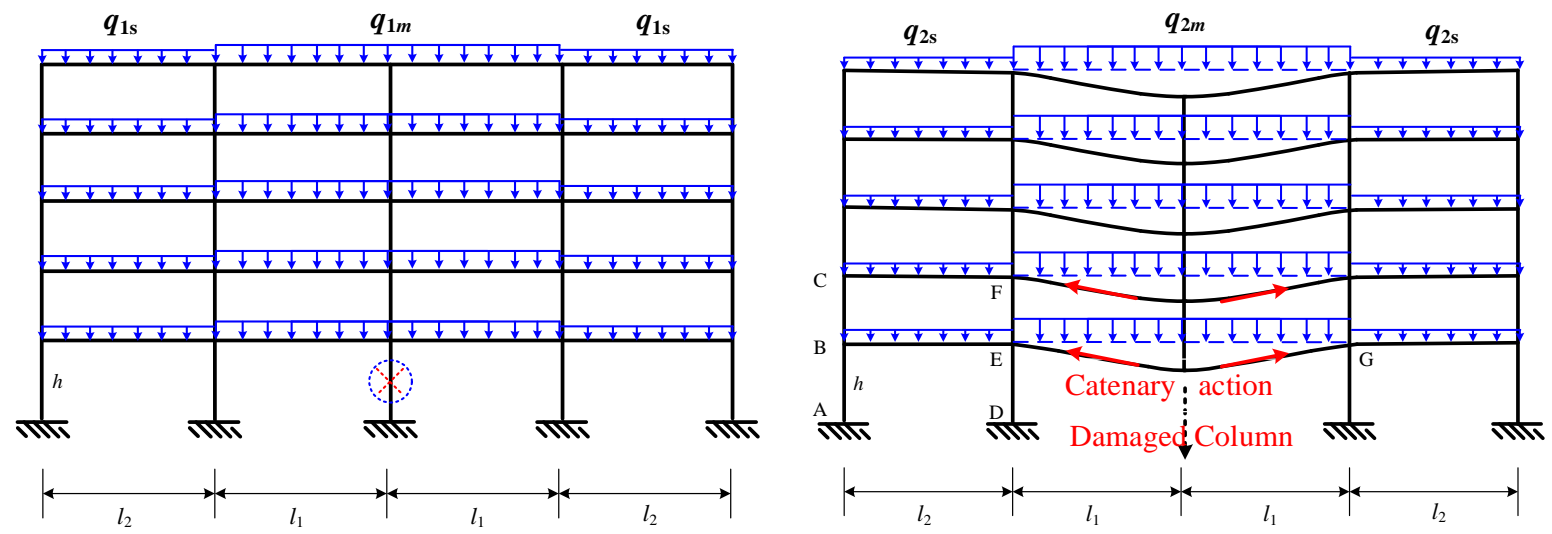

Fig. 6 Schematic of robustness index

(b) damaged structure 


\subsubsection{Dynamic amplification factor and collapse mode}

The determination of $I_{\text {rob }}$ depends on the dynamic amplification factor $\gamma$ and collapse mode [61]. Finite element models were established in ABAQUS and validated against experimental results. A push-down analysis was then carried out for the three tested steel frames. The predicted static load corresponding to a vertical displacement equal to the measured value of $0.252 \mathrm{~m}$ is $P_{1 \mathrm{~m}}=4.42 \mathrm{kN}$, compared to the applied load of $3.3 \mathrm{kN}$. Thus, the dynamic amplification factor can be determined as $\gamma_{1}=4.42 / 3.3=1.34$. Similarly, the dynamic amplification factors of FRAME2 and FRAME3 were determined as $\gamma_{2}=4.23 / 3.85=1.10$ and $\gamma_{3}=4.57 / 3.85=1.19$, respectively. It is worth noting that the dynamic amplification factors are much less than a conventional value of 2.0. This can be attributed to the energy dissipation from the development of plastic deformations in the frame.

Two collapse modes were found depending on the behaviour of connections and columns, as shown in Fig. 7. If the collapse of the frame is triggered by fracture of beams or connections, the collapse of the frame will be limited in the damaged bays, which is defined as a confined collapse mode (Fig. 7a). If the connection is sufficiently strong and ductile, the local failure will spread beyond to the surrounding columns, leading to a propagating collapse mode (Fig. 7b).

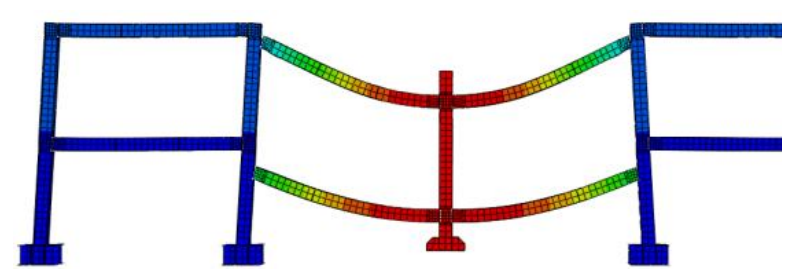

(a) confined collapse mode

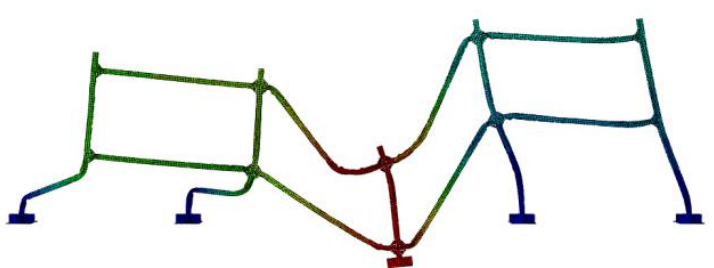

(b) propagating collapse mode

Fig. 7 Two collapse modes of steel frames

\subsubsection{Parametric studies}

Parametric studies were conducted to investigate the influencing of strain rate of materials, damping ratio, sizes of beams and columns, and location of removed columns. The details can be found in the reference [60]. The results showed that: (1) For a confined collapse mode, the influence of material strain rate was larger than that of the damping ratio; (2) For the propagating collapse mode, the influence of damping was larger than that of strain rate; (3) the ultimate load and robustness increased with increasing damping ratios; (4) The ultimate load and robustness for a middle column removal was larger than that for a side-bay column removal.

\section{Collapse behavior of buldings subject to blast}

This section addressed the influence of failure time and residual bearing capacity of the damaged column on the resistance of the whole structure

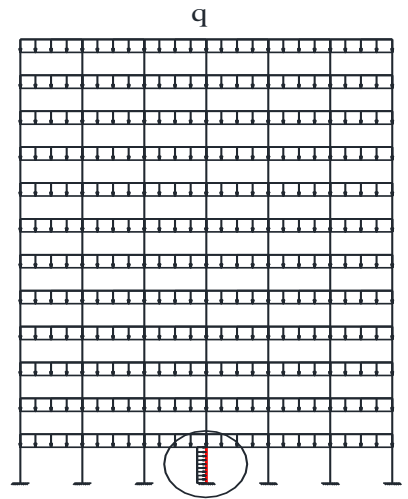

Fig. 8 A steel frame subjected to explosion on a ground floor column

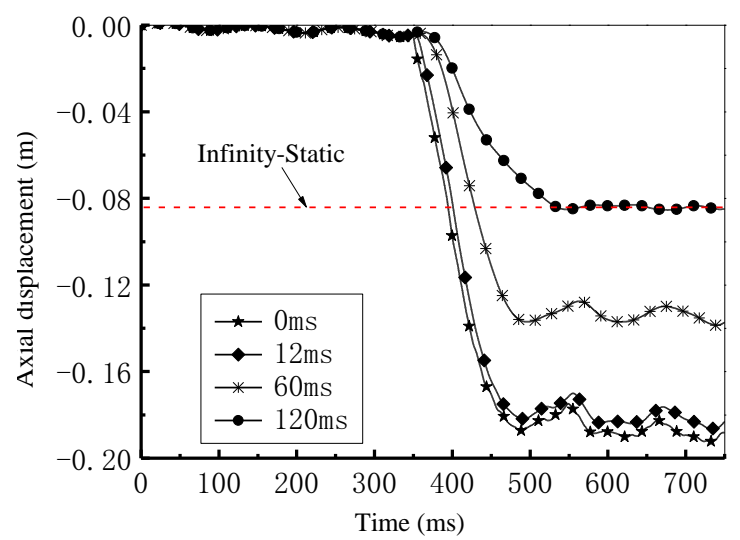

Fig. 10 Vertical displacement of the column versus time for different failure times against progressive collapse. A 2D steel frame of six bays and twelve storey was modeled in this study, as shown in Fig. 8 [62]. The span and storey height of the frame were taken as $4.5 \mathrm{~m}$ and $3 \mathrm{~m}$, respectively. The I-type steel beams and columns were taken as $\mathrm{I} 400 \times 200 \times 8 \times 10 \mathrm{~mm}$ and $\mathrm{I} 500 \times 500 \times 12 \times 15 \mathrm{~mm}$, respectively. A vertical uniformly distributed load of $q=75 \mathrm{kN} / \mathrm{m}$ was applied on all the beams, and a lateral blast load on the ground floor column. For an identified blast load acting on the column, the axial force in the column may decrease from its initial value $N_{0}$ to $N^{\prime}$ as show in Fig. 9. After the explosion, the frame will continue to deform under the vertical loads and thus the damaged column reaches its residual load-bearing capacity $N_{\mathrm{r}}$. The influence of the failure time $t_{0}$ and residual bearing capacity $N_{\mathrm{r}}$ of the blast-exposed column on the vertical displacement of the frame was studied as follows.

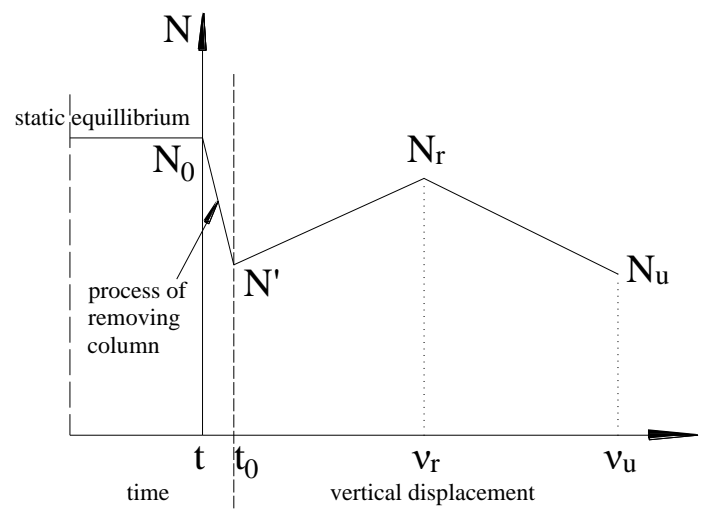

Fig. 9 Variation of the axial force in the column under explosion

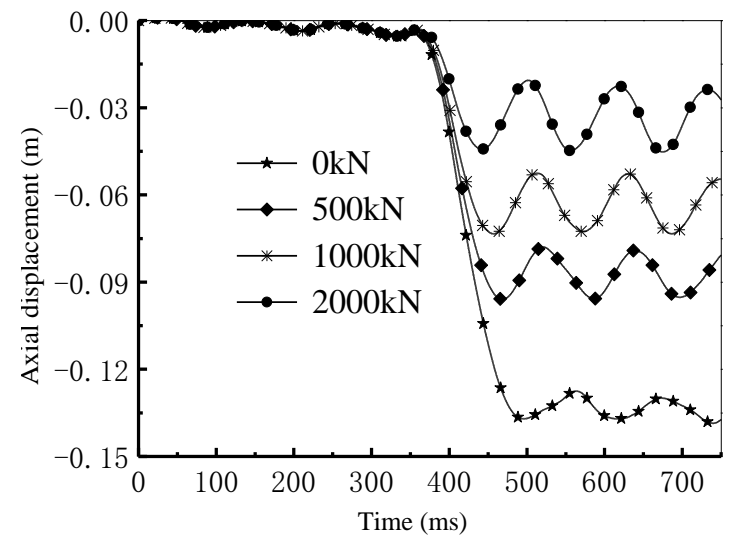

Fig. 11 Comparison of axial displacements of columns for different residual capacities 


\subsection{Influence of failure time to}

The residual bearing capacity model $\left(N_{\mathrm{r}}=8000 \mathrm{kN}\right)$ of the column under explosion in Fig. 9 was used in this case. Five cases of failure time of the column were adopted $(0 \mathrm{~ms}, 12 \mathrm{~ms}, 60 \mathrm{~ms}, 120 \mathrm{~ms}$, infinity). Comparison of the axial displacement at the column top for the five failure cases is shown in Fig. 10. The longer the failure time of the column, the less the displacement of the structure. When the failure time was infinite, the displacement is equivalent to the static response. Obvious dynamic effects were observed for an immediate removal $(0 \mathrm{~ms})$. The response for a removal of $12 \mathrm{~ms}$ almost coincided with the immediate removal. This indicates that only if the failure time is within certain range (e.g. $60 \mathrm{~ms}$ ), it is important to consider the effect of failure time of columns.

\subsection{Influence of residual load-bearing capacity $\mathrm{Nr}$}

The same failure time of $60 \mathrm{~ms}$ was taken. Four conditions of residual load-bearing capacity $N_{\mathrm{r}}$ of the column were considered $(0 \mathrm{kN}, 500 \mathrm{kN}, 1000 \mathrm{kN}$, $2000 \mathrm{kN}$ ). Fig. 11 shows the variation of axial displacements of the column for the four residual capacity cases. It showed that the larger the residual bearing capacity of the column, the less the displacement of the structure given the same failure time. Therefore, the existence of the residual bearing capacity can enhance the collapse resistance of structures. Therefore, it is important to consider the residual bearing capacity of the damaged column under explosion for assessing the collapse resistance of structures.

An equivalent spring model and SDOF model were proposed by the authors to simplify the analysis of progressive collapse of steel framed structures. The equivalent spring model includes two independent steps: (1) determine the failure process (failure time and residual load-bearing capacity) of the column under blast based on a member-level model; (2) replace the damaged column with an equivalent spring model considering the column failure process, and analyze the behavior of the remaining structure. The SDOF model is to further simplify the analysis, and to analytically determine the failure time and residual load-bearing capacity of columns under blast. The detailed development and verification of these two models are presented in the reference [62].

\section{Collapse behavior of buildings subject to fire}

\subsection{Experimental study}

Fire tests were carried out to investigate the collapse resistance of steel frames under localized fires [63]. Three planar steel frames (Frames 1, 2 and 3) were designed and tested, as shown in Fig.12. The test frames had 4 bays and 2 storeys. The spans of the two middle and edge bays were $2.2 \mathrm{~m}$ and $2.0 \mathrm{~m}$, respectively. The column in the middle of the ground floor (gridline 3) was heated by an electric furnace. Frame 1 had a larger rectangular tube section of middle bay columns $(150 \times 50 \times 5)$, compared to $60 \times 40 \times 3.5$ of Frame 2 and Frame 3. A larger gravity load was applied on Frame 3 . The electric furnace is designed to allow dynamic performance and large deflection of the test frames (Fig. 12b). Gravity loadings were imposed to the frame by hanging weight baskets on the beam (Fig. 12b). Welded beam-to-column connections were used.

The vertical displacements at the top of the heated columns of the three frames were measured and compared in Fig. 13. It shows that the displacement descended gradually in Frame 1 while changed rapidly in Frames 2 and 3. This indicates that the heated column in Frame 1 failed in a quasi-static way, whereas those of Frames 2 and 3 failed in a dynamic way. This is because of the stronger axial restraint stiffness of the heated column in Frame 1 and less load level imposed to Frame 1. Besides, Frames 2 and 3 regained equilibrium after failure of the heated column, when the displacement reached around $55 \mathrm{~mm}$ and $420 \mathrm{~mm}$, respectively, as shown in Fig. 14.

The experimental results showed that, depending on the restraining condition and loading level, the failure process of a restrained steel column in fire could be either static or dynamic. Ignoring the dynamic effect on structural behavior under fire may greatly underestimate the maximum displacement of structures, thus leading to an unsafe design.

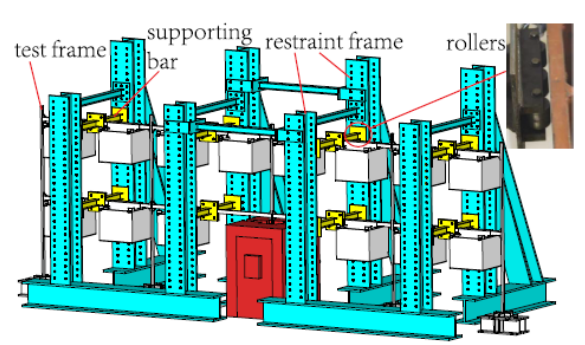

(b) loading system

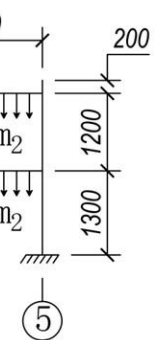

(5)

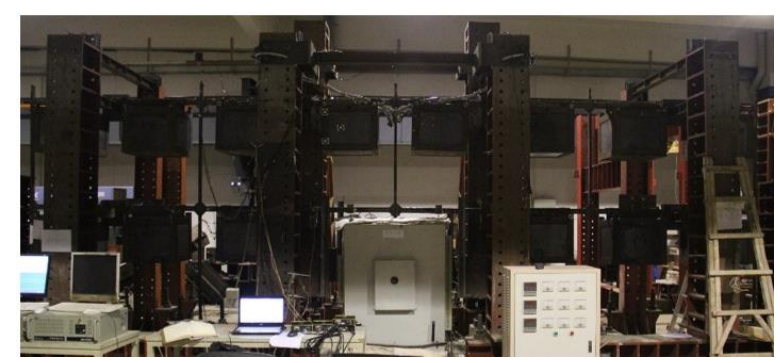

(c) on-site setup

Fig. 12 Layout of fire tests on steel frames

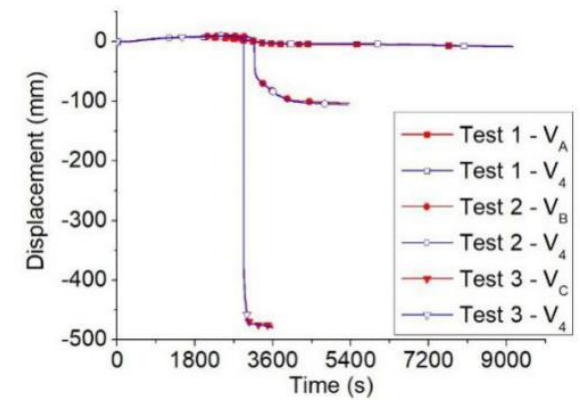

Fig. 13 Comparison between two displacement measurement systems for the vertical displacement at the top of the frames

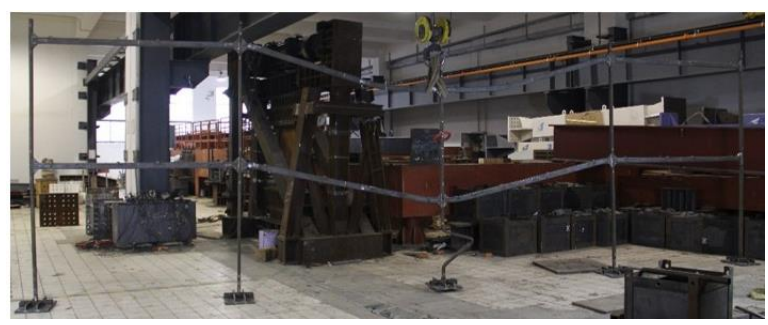

Fig. 14 Deformation of Frame 3 after test 


\subsection{Numerical study}

Numerical simulation of the test frames using the software ABAQUS was conducted to further investigate the collapse mechanism of the test frames [63]. Fig. 15 shows the numerical model and the analysis results of test frame 3 . It shows that the numerical analysis results agreed well with the test results in terms of both the deformation shape and the displacement of the test frame.

Parametric studies were conducted to study the influence of damping and the strain rate of material on the performance of steel frames under localized fires by using the numerical model of Frame 2. The results showed that the damping with damping ratios ranging from 0 to $10 \%$ had a negligible influence on the performance of frames as shown in Fig. 16. The influence of material strain rate was significant for the cases when the heated column failed in a dynamic way as shown in Fig. 17. Neglecting the strain rate effect in the numerical modelling may significantly overestimate the maximum displacement at top of the heated column.

The validated numerical models were further used to study the collapse modes of frames through amplifying the applied gravity load. As shown in Fig. 18a, after the failure of the heated column, the deflection of beams above the column was small. The failure of the heated column resulted in an increment of compressive axial forces in the adjacent column, leading to their buckling. This collapse mode can be defined as Column-buckling failure mode, which may occur when the beams are strong and the initial load ratio is high [31]. Fig. $18 \mathrm{~b}$ shows large deflections of beams, and obvious lateral displacements of the adjacent columns. This mode can be identified as Pulling-in force induced failure [31]. This collapse mode is prone to occur for the frames with weak beam sections [31]
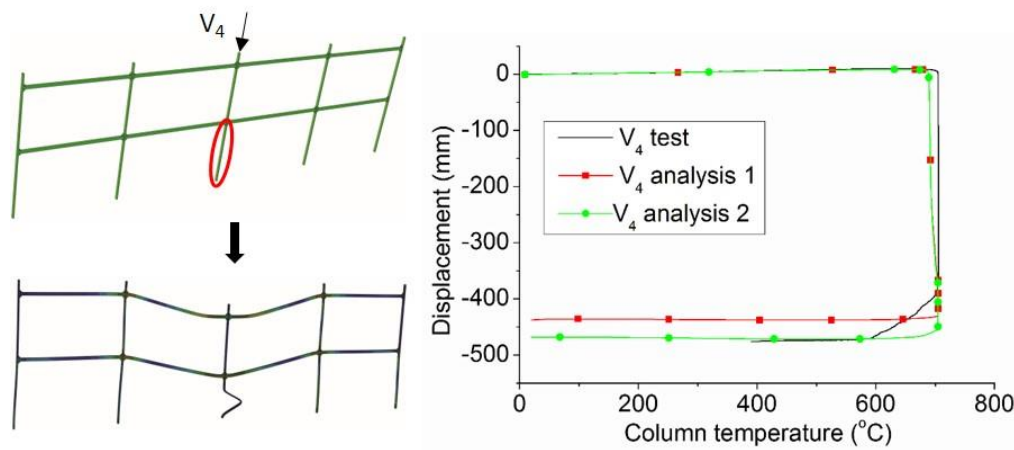

Fig. 15 Numerical analysis of Frame 3

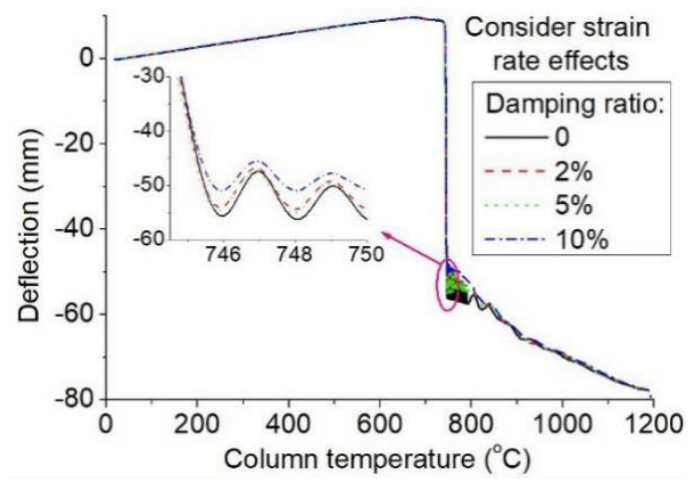

Fig. 16 Effect of damping on vertical displacement (V4) at top of the heated column

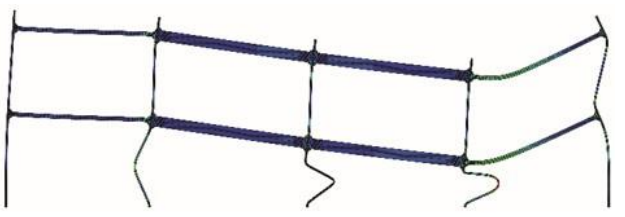

(a) column buckling failure mode (Frame 1)

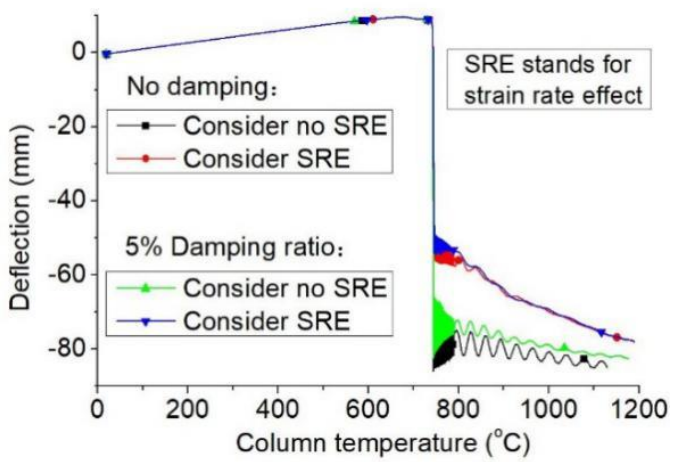

Fig. 17 Effect of strain rate effect on vertical displacement (V4) at top of the heated column

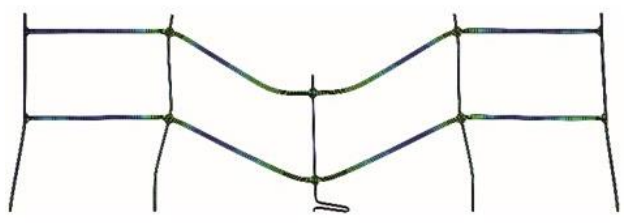

(b) pull-in force induced failure mode (Frames 2 and 3)

Fig. 18 Failure modes of the test frames

\section{Effect of slabs and beams on collapse resistance}

When a structure experiences large deformations, a secondary load resisting mechanisms such as the tensile membrane action in slabs and catenary action in beams will be mobilized as an effective means against collapse. This section presents an experimental study on a 3D steel frame due to an edge-column loss. Moreover, energy-based analytical approaches were proposed to quantify the collapse resistance of steel structures in the event of a general middle and side column loss scenario, as shown in Fig. 19.

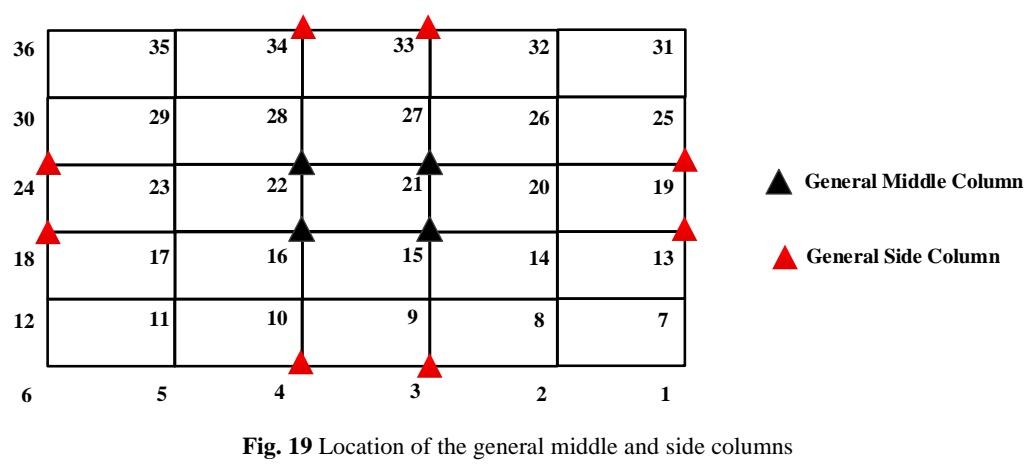




\subsection{Experimental study}

The specimen was a single-storey, two-bay steel frame with flat concrete slabs [67], as shown in Fig. 20. The height is $1.3 \mathrm{~m}$. The transverse and longitudinal spans of the slab are $1.8 \mathrm{~m}$ and $2.4 \mathrm{~m}$, respectively, as illustrated in
Fig. 21. The test setup is shown in Fig. 22. A force was applied at the columnremoval location by the actuator, as shown in Fig. 23. A force-controlled loading rule was used and when the load exceeded $80 \mathrm{kN}$, displacementcontrolled loading rule was employed.

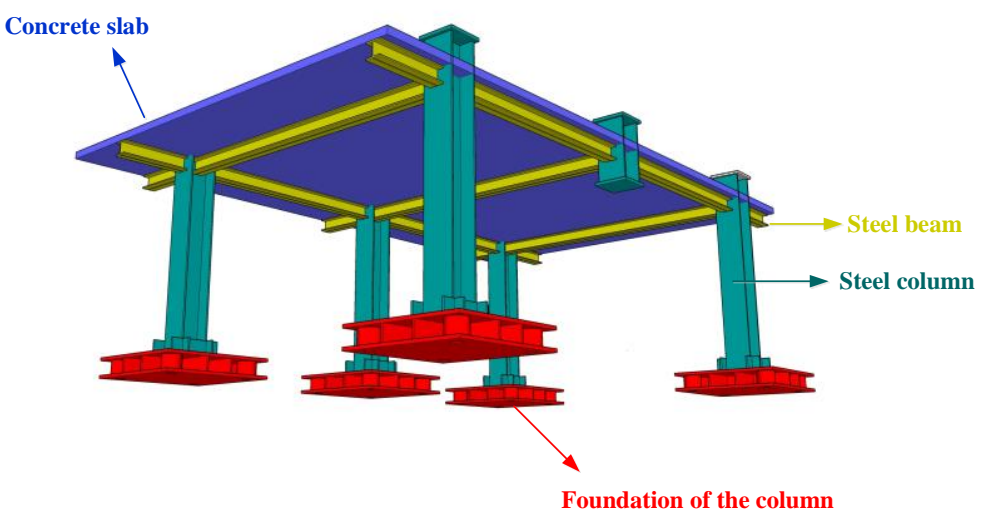

Fig. 20 The test specimen

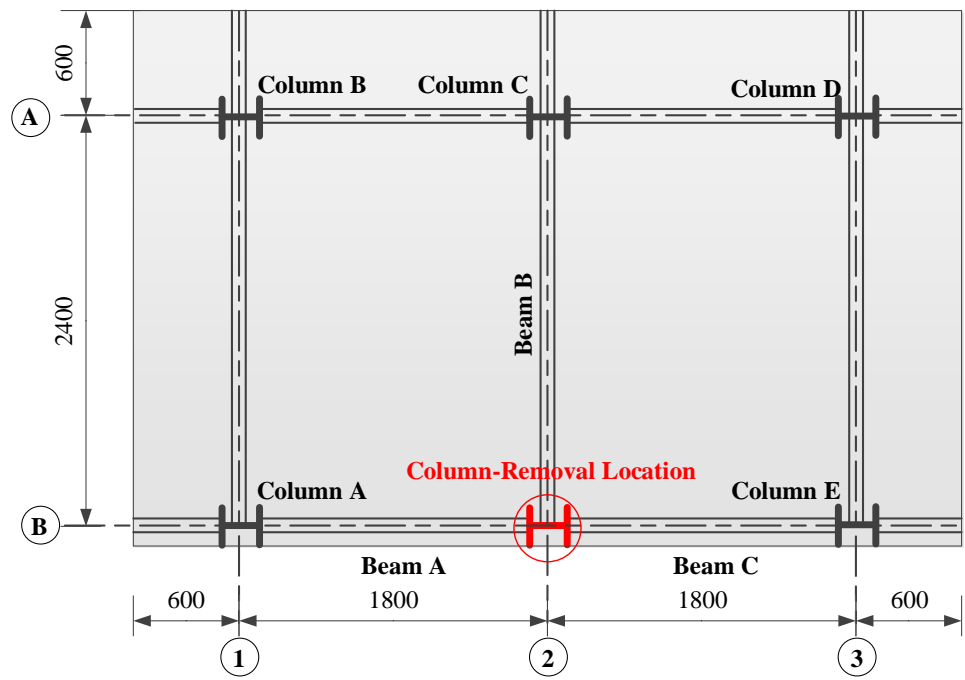

Fig. 21 Plan view of the tested frame. (Dimensions in mm.)

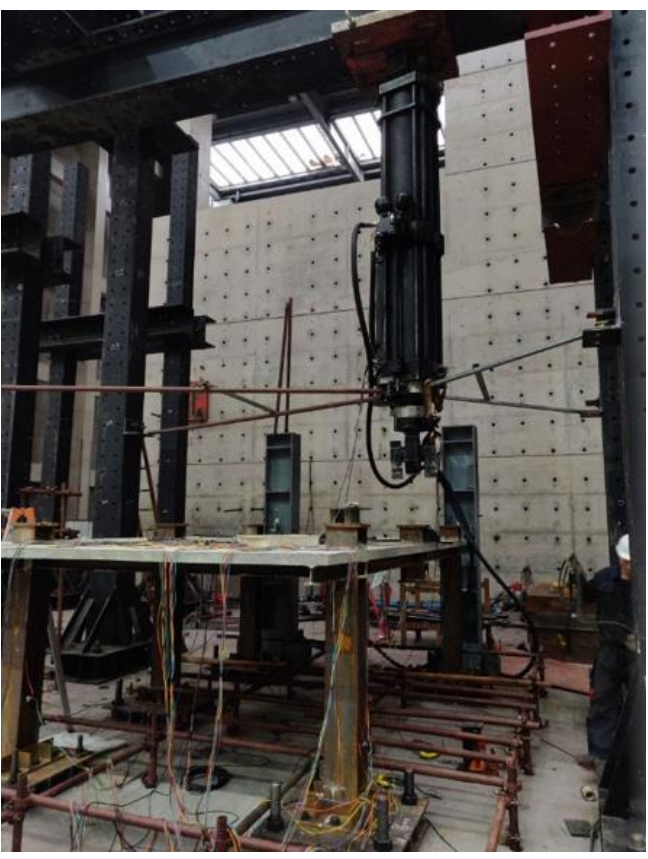

(a) On-site layout

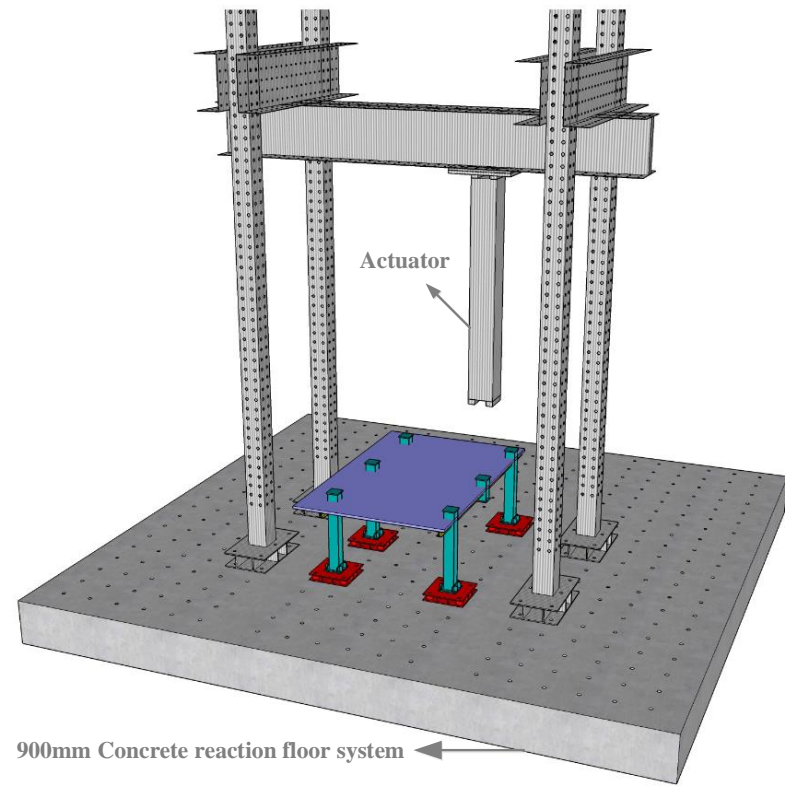

(b) Schematic layout

Fig. 22 Test setup 


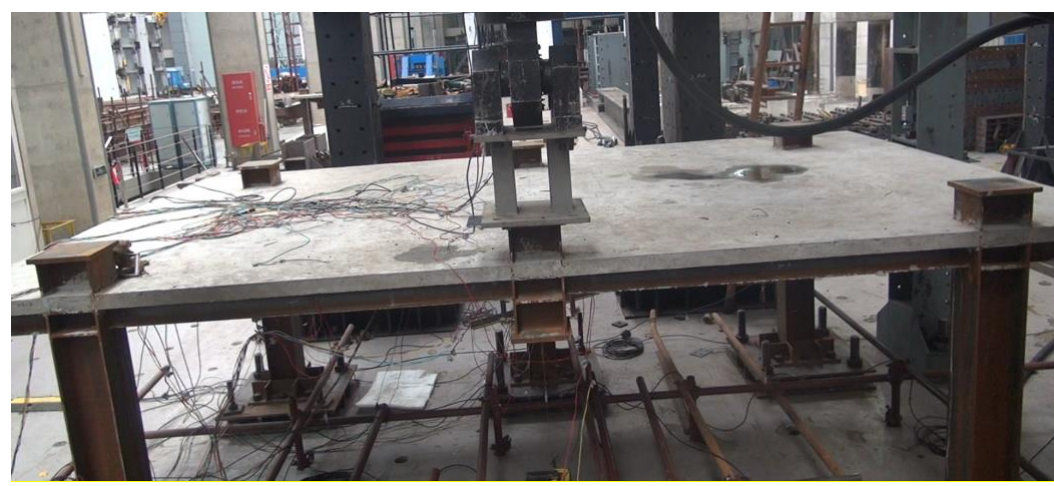

Fig. 23 Connection between the actuator and the specimen

The displacement-resistance relationship of the frame is shown in Fig. 24. The collapse resistance and final displacement are $227 \mathrm{kN}$ and $606 \mathrm{~mm}$, respectively. Three stages were found for the curve: elastic-plastic stage, transition stage, an catenary action stage. It was found that the collapse resistance of the frame was about 2.8 times greater than its plastic bearing capacity.

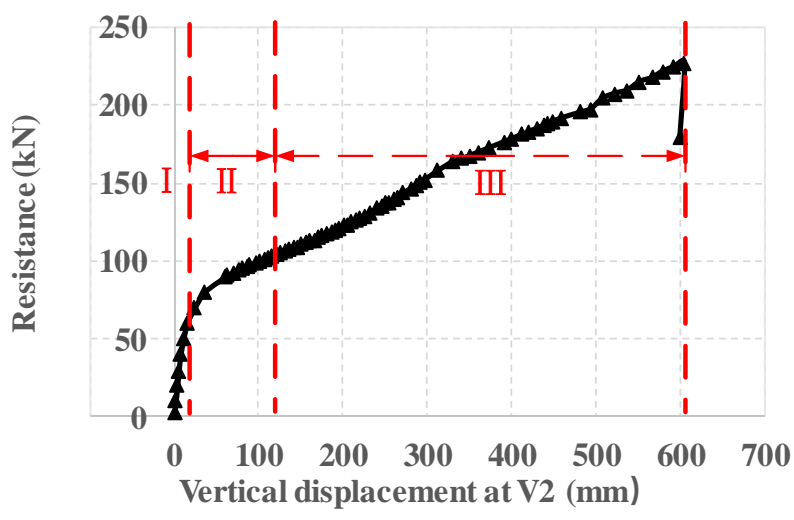

Fig. 24 Resistance-vertical displacement curve of the tested frame

The final deformation shapes of the frame are shown in Fig. 25 Fig. 27. As shown in Fig. 25, a main crack which elliptically distributed along the edges was found on the slab top. Obvious spalling of concrete from the column-removal location to the corner columns was observed. The failure of the frame was governed by fracture of the bottom flange of steel beams, as shown in Fig. 26. The deformation shape of the column at corner is shown in Fig. 27. There was severe local buckling at the bottom of the column.

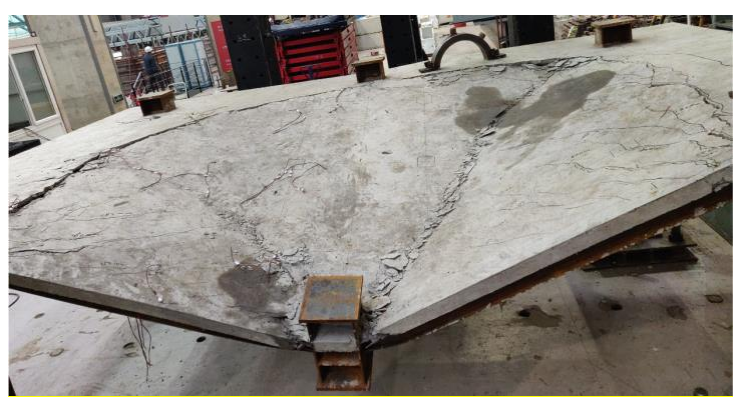

(a) Front view

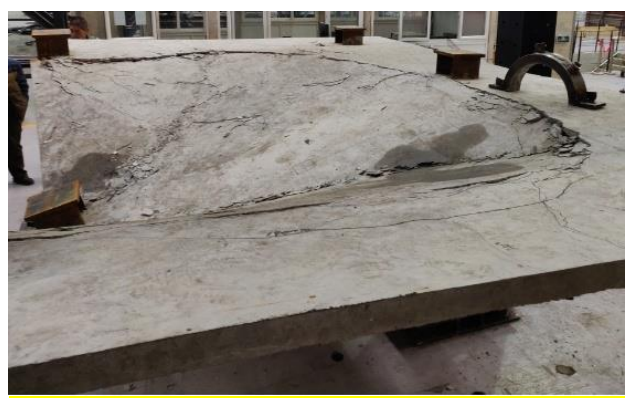

(b) Right view

Fig. 25 Final deformation shape of slabs

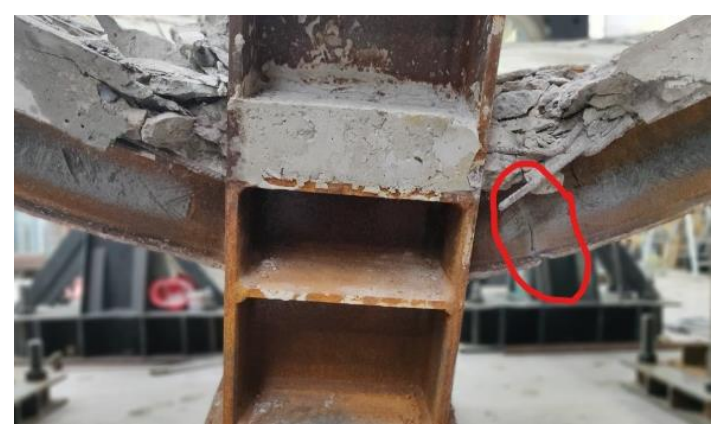

Fig. 26 Fracture of steel beams

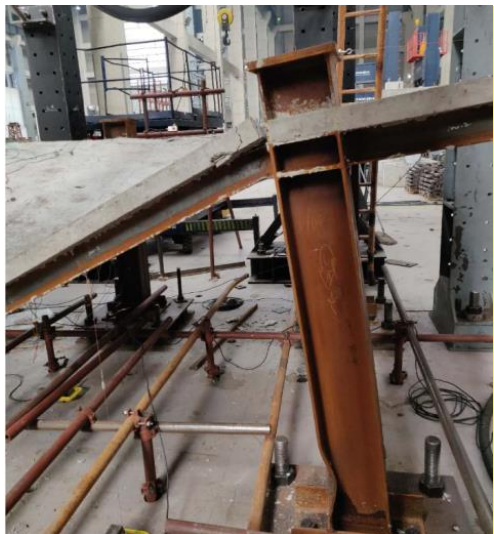

Fig. 27 Lateral displacement of columns 


\subsection{Analytical study}

\subsubsection{Model simplification}

To save computational cost, the collapse resistance of the remaining framed-structure after column loss is represented by the corresponding simplified substructures. Fig. 28 Fig. 29 show the simplifications of the

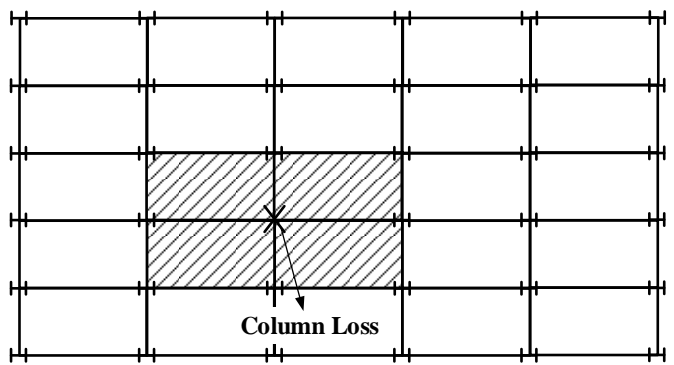

(a) original structure for general middle column loss scenario substructures for general middle and side column loss scenarios, respectively. For the general middle column loss scenario, the boundary conditions for the four edges of the substructure are fully restrained considering that the axial and rotational restraints provided by the surrounding slabs and beams are relatively strong. Similarly, for the general side column loss scenario, three edges of the substructure are fully restrained.

Fig. 28 Model simplification for general middle column loss scenario [65]

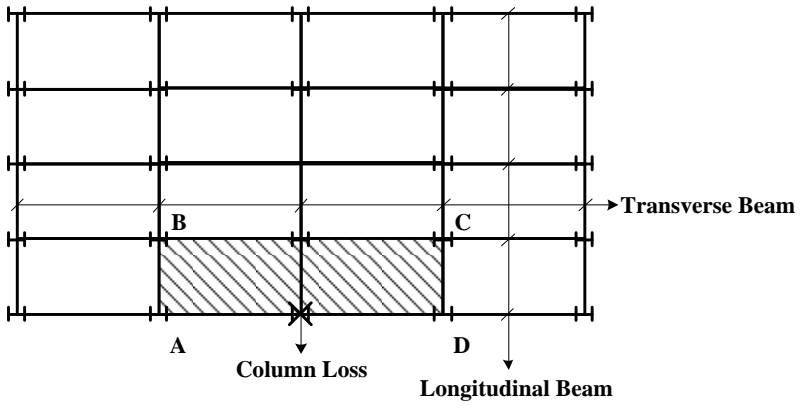

(a) original structure for general side column loss scenario

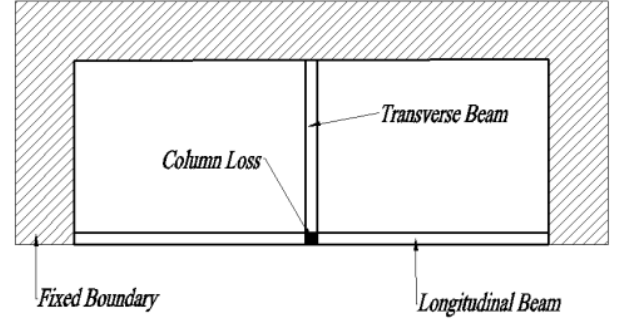

(b) simplified slab-beam substructure for general side column loss scenario

Fig. 29 Model simplification for general side column loss scenario [66]

\subsubsection{Analytical model}

The failure modes of the substructure under the removal of middle and side columns are shown in Fig. 30. For the middle-column removal scenario, the failure mode of the composite beam-slab substructure is shown in Fig. 30 (a) [65]. This substructure can be divided into four rigid segments by the positive yield lines AI, CI, EI and GI. An elliptical and negative yield line was hypothesized to emerge along the edges of the substructure. For the sidecolumn removal, the failure mode is indicated in Fig. 30(b) [66]. The

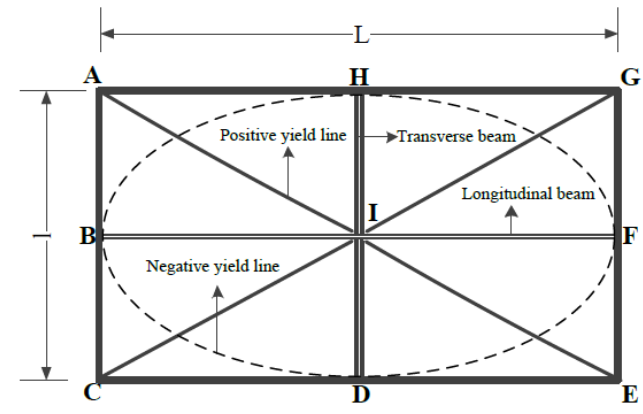

(a) failure mode for general middle column loss scenario substructure is divided into three rigid segments by the positive yield lines AJ and $\mathrm{KC}$, and the negative yield lines BL and MD were used to emerge for the unevenly distributed deformation. Note that the resistance of steel beams at the limit state is dominated by catenary action, which indicates that the bending action is negligible. Thus, the formation of plastic moment hinges was ignored in the assumed failure mode of steel beams.

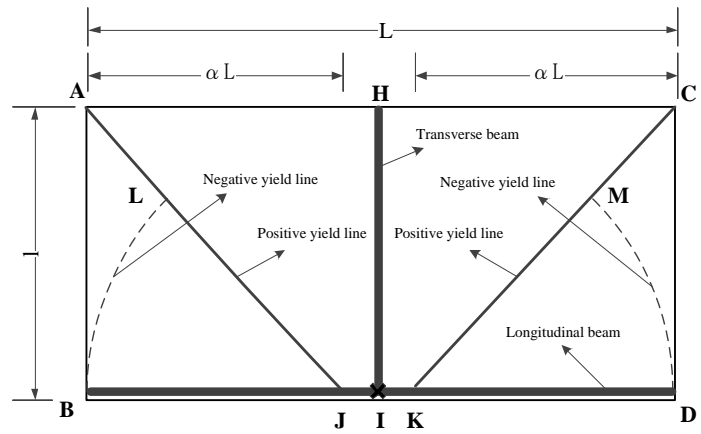

(b) failure mode for general side column loss scenario

Fig. 30 Failure modes for general middle and side column loss scenario $[64,65]$

For calculating the collapse resistance of the beam-slab substructure in the proposed energy-based method, the following three internal energy dissipations were considered: (1) elongation of reinforcement bars in the slab along yield lines and steel beams; (2) additional resultant moment due to the tensile membrane force in the slab and tensile force in the beam; (3) sectional bending moment along the yield lines. The detailed deduction of this analytical approach can be found in the references $[65,66]$. The ultimate capacity of the substructure can be obtained using the proposed energy-based method. For the general middle column loss, the ultimate capacity is given by:

$$
\begin{aligned}
& F=\left(C_{x e}\left(T_{x} l+2 F_{u L}\right)+C_{y e}\left(T_{y} L+2 F_{u T}\right)+4 C_{a} T_{y} L b \frac{v}{l}+4 \frac{F_{u T}}{l} v\right. \\
& \left.+4 C_{a} T_{x} l b \frac{v}{L}+4 \frac{F_{u L}}{L} v+4 C_{y m} M_{y} \frac{L}{l}+4 C_{x m} M_{x} \frac{l}{L}+4 M_{y}^{\prime} \frac{L}{l}+4 M_{x}^{\prime} \frac{l}{L}\right)
\end{aligned}
$$

For the general side column loss, it is given by:

$$
\begin{aligned}
& F=\left(C_{x e}\left(T_{x} l+2 F_{u L}\right)+2 C_{y a} T_{y} L b \frac{v}{2 l}+2 C_{x a} T_{x} l b \frac{v}{\alpha L}+2 F_{u L} \frac{v}{\alpha L}\right. \\
& \left.+2 C_{y m} M_{y} \alpha \frac{L}{l}+2 C_{x m} M_{x} \frac{l}{\alpha L}+2 M_{x}^{\prime} \frac{l}{\alpha L}\right)
\end{aligned}
$$


where $C_{x e}$ and $C_{y e}$ represent the contribution from the extended reinforcement and beams, respectively; $C_{a}$ represents the contribution from additional bending moments caused by membrane forces in slabs; $C_{y m}$ and $C_{x m}$ represent the influence of the membrane force on the yield bending moment of slabs, respectively.

To capture the main mechanical characteristics of the substructures at large deflections, a tri-linear displacement-resistance relationship was proposed. As shown in Fig. 31, $v_{A}, v_{B}$ and $v_{C}$ are the displacement corresponding to the end of the elastic-plastic stage, transition stage and failure displacement, respectively. $q_{A}$ is the plastic capacity of the substructure, which can be determined by yield-line theory. The determinations of displacements $v_{A}$ and $v_{B}$ are included in Ref. [65, 66].

\subsubsection{Verification}

The performance of the proposed analytical method was verified by validated numerical models, wherein the effect of structural parameters such as aspect ratio and thickenss of slabs, reinforcement ratio of slabs, height of beam section on the progressive collapse of beam-slab composite substructures were considered. The detailed parameters of substructures for removal of a middle and side column are given in Tables 2 and 3, respectively. The comparisons of analytical and numerical displacement-resistance relationships of the substructures under removal of a middle and side column were shown in Ref. [65] and Ref. [66], respectively. The errors of the predicted ultimate bearing capacity of the substructures are shown in Tables 4 , respectively. The proposed method provided accurate predictions on the ultimate bearing capacity of the substructure, with the relative errors less than $15 \%$.

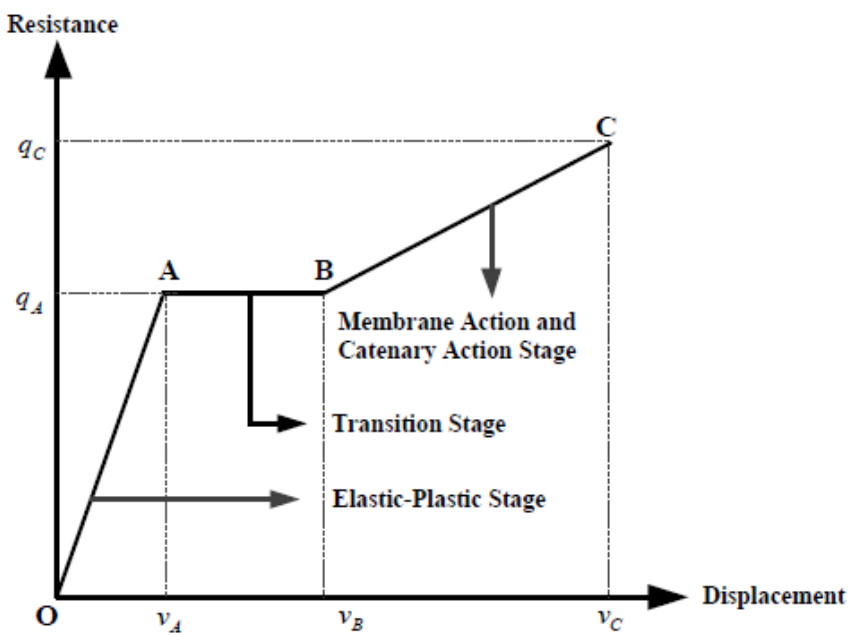

Fig. 31 Simplified resistance-displacement curve

Table 2

Dimensions and reinforcement of the composite substructures for middle column loss scenario

\begin{tabular}{|c|c|c|c|c|c|c|}
\hline \multirow{2}{*}{ No. } & \multirow{2}{*}{ Variable } & \multirow{2}{*}{$\begin{array}{l}\text { Planar Size } \\
(\mathrm{L} \times 1)(\mathrm{mm})\end{array}$} & \multirow{2}{*}{$\begin{array}{l}\text { Slab Thickness } \\
\qquad(\mathrm{mm})\end{array}$} & \multicolumn{2}{|c|}{ Reinforcement } & \multirow{2}{*}{ Beam Section } \\
\hline & & & & Top & Bottom & \\
\hline $\mathrm{S} 1$ & Control specimen & $4000 \times 3000$ & 100 & Ф12@120 & $\Phi 12 @ 180$ & $200 \times 100 \times 5.5 \times 8$ \\
\hline $\mathrm{S} 2$ & & $4000 \times 2500$ & 100 & Ф12@120 & $\Phi 12 @ 180$ & $200 \times 100 \times 5.5 \times 8$ \\
\hline S3 & Aspect ratio & $4000 \times 3500$ & 100 & Ф12@120 & Ф12@180 & $200 \times 100 \times 5.5 \times 8$ \\
\hline S4 & & $4000 \times 4000$ & 100 & Ф12@120 & $\Phi 12 @ 180$ & $200 \times 100 \times 5.5 \times 8$ \\
\hline S5 & & $4000 \times 3000$ & 75 & Ф12@120 & $\Phi 12 @ 180$ & $200 \times 100 \times 5.5 \times 8$ \\
\hline S6 & Slab thickness & $4000 \times 3000$ & 125 & Ф12@120 & Ф12@180 & $200 \times 100 \times 5.5 \times 8$ \\
\hline S7 & & $4000 \times 3000$ & 150 & Ф12@120 & $\Phi 12 @ 180$ & $200 \times 100 \times 5.5 \times 8$ \\
\hline S8 & & $4000 \times 3000$ & 100 & Ф14@120 & $\Phi 14 @ 180$ & $200 \times 100 \times 5.5 \times 8$ \\
\hline S9 & Rebar ratio & $4000 \times 3000$ & 100 & Ф8@120 & Ф8@180 & $200 \times 100 \times 5.5 \times 8$ \\
\hline S10 & & $4000 \times 3000$ & 100 & $\Phi 10 @ 120$ & $\Phi 10 @ 180$ & $200 \times 100 \times 5.5 \times 8$ \\
\hline S11 & & $4000 \times 3000$ & 100 & Ф12@120 & Ф12@180 & $120 \times 100 \times 5.5 \times 8$ \\
\hline $\mathrm{S} 12$ & Beam section height & $4000 \times 3000$ & 100 & Ф12@120 & Ф12@180 & $160 \times 100 \times 5.5 \times 8$ \\
\hline S13 & & $4000 \times 3000$ & 100 & Ф12@120 & $\Phi 12 @ 180$ & $240 \times 100 \times 5.5 \times 8$ \\
\hline
\end{tabular}

Note: Dimensions in mm. $\Phi$ denotes the diameter of reinforcement bars.

Table 3

Dimension and reinforcement of composite substructures for side column loss scenario

\begin{tabular}{|c|c|c|c|c|c|c|}
\hline \multirow{2}{*}{ No. } & \multirow{2}{*}{ Variable } & \multirow{2}{*}{$\begin{array}{l}\text { Planar Size } \\
(\mathrm{L} \times 1)(\mathrm{mm})\end{array}$} & \multirow{2}{*}{$\begin{array}{l}\text { Slab Thickness } \\
(\mathrm{mm})\end{array}$} & \multicolumn{2}{|c|}{ Reinforcement } & \multirow{2}{*}{ Beam Section } \\
\hline & & & & Top & Bottom & \\
\hline SS1 & Control specimen & $4000 \times 2000$ & 100 & $\Phi 12 @ 120$ & Ф12@180 & $200 \times 100 \times 5.5 \times 8$ \\
\hline SS2 & & $4000 \times 1750$ & 100 & $\Phi 12 @ 120$ & Ф12@180 & $200 \times 100 \times 5.5 \times 8$ \\
\hline SS3 & Aspect ratio & $4000 \times 2250$ & 100 & $\Phi 12 @ 120$ & Ф12@180 & $200 \times 100 \times 5.5 \times 8$ \\
\hline SS4 & & $4000 \times 2500$ & 100 & Ф12@120 & Ф12@180 & $200 \times 100 \times 5.5 \times 8$ \\
\hline SS5 & & $4000 \times 2000$ & 75 & $\Phi 12 @ 120$ & Ф12@180 & $200 \times 100 \times 5.5 \times 8$ \\
\hline SS6 & Slab thickness & $4000 \times 2000$ & 125 & Ф12@120 & Ф12@180 & $200 \times 100 \times 5.5 \times 8$ \\
\hline SS7 & & $4000 \times 2000$ & 150 & $\Phi 12 @ 120$ & $\Phi 12 @ 180$ & $200 \times 100 \times 5.5 \times 8$ \\
\hline SS8 & & $4000 \times 2000$ & 100 & Ф14@120 & Ф14@180 & $200 \times 100 \times 5.5 \times 8$ \\
\hline SS9 & Rebar ratio & $4000 \times 2000$ & 100 & Ф16@120 & Ф16@180 & $200 \times 100 \times 5.5 \times 8$ \\
\hline SS10 & & $4000 \times 2000$ & 100 & Ф10@120 & Ф10@180 & $200 \times 100 \times 5.5 \times 8$ \\
\hline SS11 & & $4000 \times 2000$ & 100 & $\Phi 12 @ 120$ & Ф12@180 & $120 \times 100 \times 5.5 \times 8$ \\
\hline $\mathrm{SS} 12$ & Beam section height & $4000 \times 2000$ & 100 & $\Phi 12 @ 120$ & Ф12@180 & $160 \times 100 \times 5.5 \times 8$ \\
\hline SS13 & & $4000 \times 2000$ & 100 & $\Phi 12 @ 120$ & Ф12@180 & $240 \times 100 \times 5.5 \times 8$ \\
\hline
\end{tabular}


Table 4

\begin{tabular}{|c|c|c|c|c|c|c|c|}
\hline \multicolumn{4}{|c|}{ Relative errors of analytical collapse resistance for middle column loss } & \multicolumn{4}{|c|}{ Relative errors of analytical collapse resistance for side column loss } \\
\hline No. & $\begin{array}{c}\text { Numerical } \\
\text { Collapse Resistance } \\
(\mathrm{kN})\end{array}$ & $\begin{array}{c}\text { Analytical } \\
\text { Collapse Resistance } \\
(\mathrm{kN})\end{array}$ & $\begin{array}{c}\text { Relative Error } \\
(\%)\end{array}$ & No. & $\begin{array}{c}\text { Numerical } \\
\text { Collapse Resistance } \\
(\mathrm{kN})\end{array}$ & $\begin{array}{c}\text { Analytical } \\
\text { Collapse Resistance } \\
(\mathrm{kN})\end{array}$ & $\begin{array}{c}\text { Relative Error } \\
(\%)\end{array}$ \\
\hline S1 & 1031 & 1011 & $1.9 \%$ & SS1 & 520.5 & 500.2 & $3.9 \%$ \\
\hline S2 & 1027 & 907 & $11.7 \%$ & $\mathrm{SS} 2$ & 522.9 & 481.7 & $7.9 \%$ \\
\hline S3 & 1037 & 1053 & $-1.5 \%$ & SS3 & 512.5 & 502.5 & $1.9 \%$ \\
\hline S4 & 1024 & 1105 & $-7.9 \%$ & SS4 & 515.9 & 525.7 & $-1.9 \%$ \\
\hline S5 & 954 & 823 & $13.7 \%$ & SS5 & 512.4 & 460.5 & $10.1 \%$ \\
\hline S6 & 1106 & 1141 & $-3.2 \%$ & SS6 & 539.8 & 543.1 & $-0.6 \%$ \\
\hline S7 & 1211 & 1321 & $-9.1 \%$ & SS7 & 555.3 & 589.4 & $-6.1 \%$ \\
\hline S8 & 1122 & 1129 & $-0.6 \%$ & SS8 & 554.5 & 532.5 & $4.0 \%$ \\
\hline S9 & 884 & 829 & $6.2 \%$ & SS9 & 582.2 & 578.9 & $0.6 \%$ \\
\hline S10 & 957 & 917 & $4.2 \%$ & SS10 & 488.3 & 454.3 & $7.0 \%$ \\
\hline S11 & 1012 & 1081 & $-6.8 \%$ & SS11 & 524.5 & 549.3 & $-4.7 \%$ \\
\hline S12 & 1018 & 1041 & $-2.3 \%$ & SS12 & 523.6 & 519.8 & $0.7 \%$ \\
\hline S13 & 1056 & 949 & $10.1 \%$ & SS13 & 498.5 & 431.2 & $13.5 \%$ \\
\hline
\end{tabular}

\subsubsection{Further discussion}

To further investigate the collapse resistance of substructures for removal of a middle and side column, the three terms of internal energy dissipations were calculated, including those from elongation of reinforcement in slabs and steel beams $W_{i n 1}$, additional resultant moment $W_{i n 2}$ and sectional moment of slabs $W_{i n 3}$ at the limit state. Fig. 32 and 33 show the proportions of these three

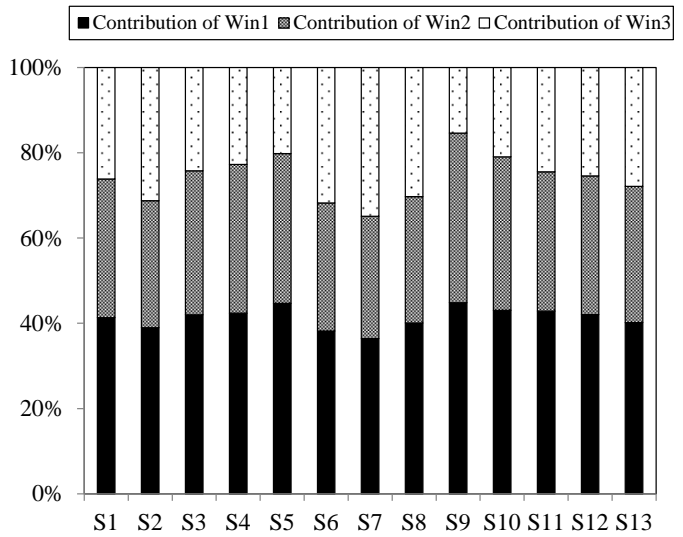

Fig. 32 Contributions from $\mathrm{W}_{i n 1}, \mathrm{~W}_{i n 2}$ and $\mathrm{W}_{i n 3}$ to the collapse resistance for middle column removal

To further verify the reliability of the proposed method, the analytical contribution percentage of the concrete slab at the ultimate limit state was compared with that of the numerical results. The numerically predicted contribution of slabs to collapse resistance was obtained by subtracting the resistance of the steel beams from the total value of the beam-slab substructure. The comparisons of the numerical and analytical slab contribution for middle and side column loss scenario are shown in Fig. 34 Fig. 35, respectively. It was found that the contribution from slabs at the collapse limit state ranged

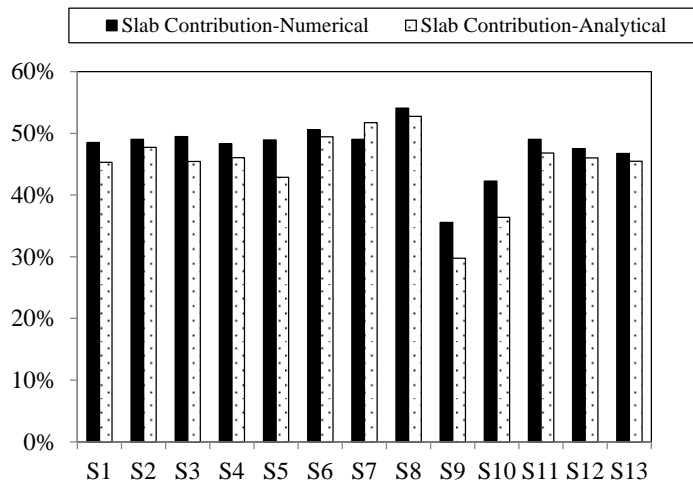

Fig. 34 Comparison of the contribution of slabs to the collapse resistance for middle column loss internal energy dissipations for the middle and side column removal, respectively. It can be concluded that the first two energy dissipations contributed more to the collapse resistance at large deflections. For the case of middle column loss, they accounted for $65 \%$ to $75 \%$ of the total energy dissipation, respectively. For side column loss, they occupied more than $70 \%$ of the total dissipation.

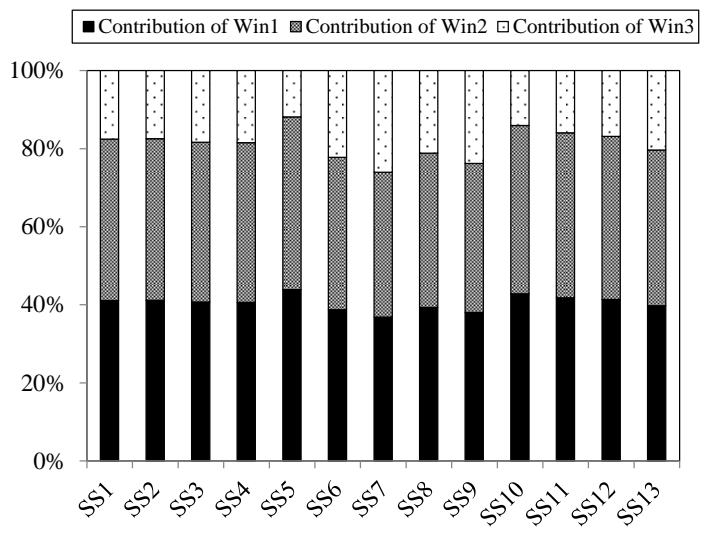

Fig. 33 Contributions from $\mathrm{W}_{i n 1}, \mathrm{~W}_{i n 2}$ and $\mathrm{W}_{i n 3}$ to the collapse resistance for side column removal

from $30 \%-50 \%$ of the total resistance, and it was mainly affected by the reinforcement ratio of slabs. When the reinforcement ratio was increased by $36 \%$, the slab-induced contribution correspondingly increased by $17 \%$ for middle column loss and $14 \%$ for side column loss. A reduction of reinforcement ratio by $56 \%$ led to decline of slab-induced contribution by $34 \%$ (middle column loss) and $31 \%$ (side column loss). The section height of beams had little effect on the beam-induced contribution to the collapse resistance of the substructure.

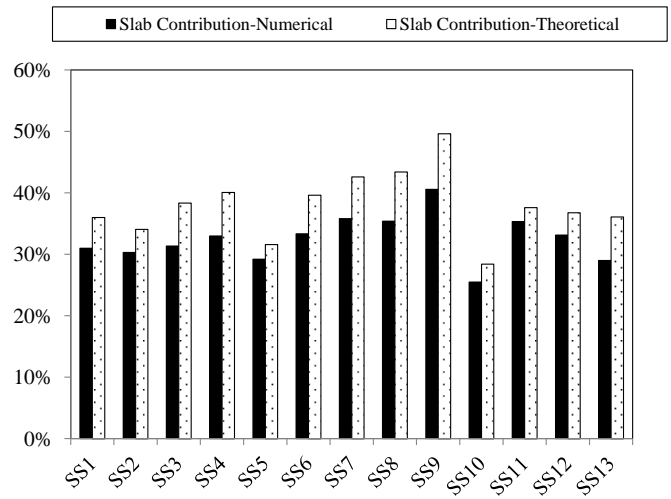

Fig. 35 Comparison of the contribution of slabs to the collapse resistance for side column loss 


\section{Conclusions}

This paper investigated progressive collapse behavior of steel framed buildings under impact, blast, and fire, respectively. Experimental, numerical and analytical studies were conducted to investigate the collapse mechanism and influencing factors. The following conclusions can be drawn:

(1) Under blast or impact, two collapse modes of steel frames were found depending on the behaviour of beams, connections and columns: beam or connection-induced collapse mode due to fracture of connections and column-induced collapse mode due to buckling of adjacent columns. In the case of fire, a similar column buckling collapse mode occurred for strong beams and high load ratio. Otherwise, the frame will collapse in a pull-in force-induced mode due to large deflection of beams.

(2) The dynamic amplification factors of frames subject to impact or blast (up to 1.35) were much less than the conventional value of 2.0, due to the energy dissipation during the plastic deformations developed in the frame. In contrast, the collapse process of frames in fire can be either static or dynamic depending on the restraint conditions and load level. It is therefore important to exactly simulate the dynamic effect of structures under extreme loads to ensure conservative conclusions.

(3) A capacity-based robustness index was proposed by comparing the imposed load on the intact structure to the residual capacity of the damaged structure. This index explicitly accounted for the dynamic effect and plastic deformation

(4) The failure process of a steel column in fire could either be quasistatic or dynamic, which is dependent on the restraint condition provided by the surrounding structural components and the load level.

(5) The influence of strain rate of material needs to be considered in the numerical modelling of structures in fire for the cases that the heated components fail in a dynamic way. Ignorance of this influence may lead to significant overestimation of the maximum deflection of the structure.

(6) Damping showed little effect on the behavior of steel frames in localized fires. Therefore, it is suggested to ignore the effect of damping for assessing progressive collapse resistance of steel frames under localized fires.

(7) An energy-based analytical approach was proposed to consider the effect of slabs and beams on the collapse behavior of structures. It was found that the energy dissipations due to the elongation of reinforcement and steel beams as well as additional resultant moment greatly contributed to the collapse resistance of the subassemblies. The slab-induced contribution was mainly affected by the slab reinforcement ratio ranging from $30 \%-50 \%$ of the total resistance.

(8) For impact or blast actions, it was found that the effect of damping on the collapse resistance depended on the collapse mode. It was larger in the column-induced collapse mode compared to beam-induced collapse mode. The ultimate load and robustness increased with increasing damping ratios. However, the damping had a negligible influence on the collapse behaviour of structures exposed to fire.

(9) It is important to consider the failure time and residual strength of blast-exposed columns for predicting the collapse resistance of structures subject to explosion.

\section{Acknowledgements}

The work presented in this paper was supported by the National Natural Science Foundation of China with grants 52078478 and 51878506 .

\section{References}

[1] Pusgley A, Griffiths H. and Saunders O. Report of the Inquiry into the Collapse of Flats at Ronan Point. Canning Town, 1968.

[2] American Society of Civil Engineers Standard 7 Minimum Design Loads for Buildings and Other Structures, American Society of Civil Engineers (ASCE), 2005.

[3] The Building Regulations: Approved Document A3: Disproportionate Collapse. Department for Transport, Environment and the Regions, DTLR, 2010.

[4] EN 1991-1-7. Actions on structures - Part 1-7: General actions -Accidental actions, European Committee for Standardisation, Brussels, 2010.

[5] McAllister T. and Corley G. World Trade Center Building performance study: Data collection, preliminary observations, and recommendations. Federal Emergency Management Agency, 2002.

[6] Design of Buildings to Resist Disproportional Collapse. Unified Facilities Criteria (UFC) 4023-03, US Department of Defense (DoD), 2010.

[7] Disproportional Collapse Analysis and Design Guidelines for New Federal Office Buildings and Major Modernization Projects, US General Services Administration (GSA), 2003.

[8] Manual for the Systematic Risk Assessment of High-risk Structures against Disproportionate Collapse. The Institute of Structural Engineers (IStructE), UK, 2013.

[9] Yu H , Izzuddin B A, Zha X X. Progressive collapse of steel-framed buildings: Influence of modelling approach[J]. Advanced Steel Construction, 2010, 6(4):932-948.

[10] Yang B. and Tan K.H., "Experimental tests of different types of bolted steel beam-column joints under a central-column-removal scenario", Engineering Structures, 54, 112-130, 2013.

[11] Lew H.S., et al., "Performance of steel moment connections under a column removal scenario. I: Experiments", Journal of Structural Engineering, 139(1), 98-107, 2012.

[12] Tsitos A., et al., "Experimental investigation of progressive collapse of steel frames under multi-hazard extreme loading", Proceedings of 14th World Conference on Earthquake Engineering, 2008.

[13] Xie F.Z. and Shu G.P., "Quasi-static experimental research on progressive collapse of space steel frames", Journal of PLA University of Science and Technology (Natural Science Edition), 14(2), 195-201, 2013. (in Chinese)

[14] Xie F.Z., "Analysis and assessment and experimental research on progressive collapse of steel frame structure". Ph.D dissertation, Southeast University, 2012. (in Chinese)

[15] Chen J. et al., "Experimental Study on the Progressive Collapse Resistance of a Two-Story Steel Moment Frame", Journal of Performance of Constructed Facilities, 26(5), 567-575, 2012.

[16] Xiao Y. et al., Collapse test of a 3-story half-scale RC frame structure. Structures Congress, ASCE, Reston, VA, 2013.

[17] Li F.W. et.al., "Experimental and analytical study on progressive collapse of RC frame with sudden side columns removal", China Civil Engineering Journal, 04(04), 9-18, 2014. (in Chinese)

[18] Sasani M. and Sagiroglu S., "Progressive Collapse Resistance of Hotel San Diego", Journal of Structural Engineering, 134(3), 478-488, 2008

[19] Sasani M. et al., "Progressive Collapse Resistance of an Actual 11-Story Structure Subjected to Severe Initial Damage", Journal of Structural Engineering, 137(9), 893-902, 2011.

[20] Krauthammer T., "Blast-resistant structural concrete and steel connections", International Journal of Impact Engineering, 22(9), 887-910, 1999.

[21] Lee C.H. et al., "Simplified nonlinear progressive collapse analysis of welded steel moment frames", Journal of Constructional Steel Research, 65(5), 1130-1137, 2009.

[22] Kripakov N.P., Sun M.C. and Donato D.A., "ADINA applied toward simulation of progressive failure in underground mine structures", Computers \& Structures, 56(2), 329344, 1995.

[23] Jian Jiang and Guo-Qiang Li. (2018) Progressive collapse of steel high-rise buildings exposed to fire: Current state of research. International Journal of High-rise Buildings, 7(4):375-387.

[24] Porcari G.L.F., Zalok E. and Mekky W., "Fire induced progressive collapse of steel building structures: A review of the mechanisms", Engineering Structures, 82, 261-267, 2015.

[25] Lange D., Roben C. and Usmani A.S., "Tall Building Collapse Mechanisms Initiated by Fire: Mechanisms and Design Methodology”, Engineering Structures, 36, 90-103, 2012.

[26] Fang C., Izzuddin B.A., Elghazouli A.Y. and Nethercot D.A., "Robustness of steelcomposite building structures subject to localized fire", Fire Safety Journal, 46, 348-363, 2011.

[27] Sun R.R., Huang Z.H. and Burgess I., "Progressive Collapse Analysis of Steel Structures under Fire Conditions", Engineering Structures, 34, 400-413, 2012.

[28] Jiang J., Li G.Q. and Usmani A.S. "Progressive collapse mechanisms of steel frames exposed to fire", Advances in Structural Engineering, 17(3), 381-398, 2014.

[29] Jiang J., Li G.Q. and Usmani A.S., "Effect of bracing systems on the fire-induced progressive collapse of steel structures", Fire Technology, 51, 1249-1273, 2015.

[30] Ali H.M., Senseny P.E. and Alpert R.L., "Lateral displacement and collapse of single-storey steel frames in uncontrolled fires", Engineering Structures, 26, 593-607, 2004.

[31] Jiang B.H., Li G.Q. and Usmani A.S., "Progressive collapse mechanisms investigation of planar steel moment frames under localized fire", Journal of Constructional Steel Research, $115,160-168,2015$.

[32] Agarwal A., and Varma A.H., "Fire induced progressive collapse of steel building structures: The role of interior gravity columns", Engineering Structures, 58, 129-140, 2014.

[33] Jiang J. and Li G.Q., "Progressive collapse analysis of 3D steel frames with concrete slabs exposed to localized fire", Engineering Structures, 149, 21-34, 2017.

[34] Sun R.R., Burgess I.W., Huang Z.H. and Dong G. "Progressive failure modelling and ductility demand of steel beam-to-column connections in fire", Engineering Structures, 89, 66-78, 2015.

[35] Jiang J. and Li G.Q., "Disproportional Collapse of 3D Steel-framed Structures Exposed to Various Compartment Fires”, Journal of Constructional Steel Research, 138, 594-607, 2017.

[36] Jian Jiang, Joseph Main, Jonathan Weigand and Fahim Sadek*. Reduced-order modeling of composite floor slabs in fire. I: Heat transfer analysis. Journal of Structural Engineering. 2020, 146(6): 04020080

[37] Jian Jiang, Joseph Main, Jonathan Weigand and Fahim Sadek*. Reduced-order modeling of composite floor slabs in fire. II: Thermal-structural analysis. Journal of Structural Engineering. 2020, 146(6): 04020081.

[38] Cowlard A., Bittern A., Abecassis-Empis C. and Torero J. Fire safety design for tall buildings. Proceedings of the 9th Asia-Oceania Symposium on Fire Science and Technology, Procedia Engineering, 62, 169-181, 2013.

[39] Jian Jiang, Adam Pintar, Jonathan M. Weigand, Joseph A. Main, and Fahim Sadek. (2019) Improved Calculation Method for Insulation-based Fire Resistance of Composite Slabs. Fire Safety Journal, 105, 144-153

[40] Jian Jiang and Guo-Qiang Li*. (2018) Parameters Affecting Tensile Membrane Action of Reinforced Concrete Floors subjected to Elevated Temperatures. Fire Safety Journal, 96: 5973.

[41] Jian Jiang, Wenyu Cai, Guo-Qiang Li*, Wei Chen and Jihong Ye. (2020) Disproportionate Collapse of steel-framed gravity buildings under Parametric Fires.Steel and Composite Structures (in press).

[42] Jiang B., Li G.Q. and Izzuddin B., "Dynamic performance of axially and rotationally restrained steel columns under fire", Journal of Constructional Steel Research, 122, 308$315,2016$.

[43] Behnam B., and Rezvani F.H., "Structural evaluation of tall steel moment-resisting structures in simulated horizontally travelling postearthquake fire", Journal of Performance of Constructed Facilities, DOI:10.1061/(ASCE)CF.1943-5509.0000696, 2015.

[44] Jian Jiang, Chenghao Wang, Guo-biao Lou, Guo-qiang Li. (2018) Quantitative Evaluation of Progressive Collapse Process of Steel Portal Frames in Fire. Journal of Constructional Steel Research, 150: 277-287.

[45] Guo-biao Lou, Chenghao Wang, Jian Jiang*, Yaqiang Jiang, Liangwei Wang, Guo-qiang Li. (2018) Fire Tests on Full-scale Steel Portal Frames Against Progressive Collapse. Journal of Constructional Steel Research, 145: 137-152. (SCI: )

[46] Jian Jiang and Guo-Qiang Li*. (2019) Mitigation of Fire-induced Disproportionate Collapse of Steel Framed Structures Using Bracing Systems. Advanced Steel Construction, 15(2), 192-202.

[47] Agarwal J., Blockley D. and Woodman N., "Vulnerability of structural systems", Structural Safety, 25(3), 263-286, 2003

[48] Huo J.S. et al. "Analysis of dynamic behavior and ductility of steel moment frame 
connections", Journal of Civil Architectural \& Environmental Engineering, 34, 149-154, 2012. (in Chinese)

[49] Frangopol D. and Curley J., "Effects of Damage and Redundancy on Structural Reliability", Journal of Structural Engineering, 113(7), 1533-1549, 1987.

[50] Beeby A., "Safety of structures, and a new approach to robustness", Structural Engineer, 77(4), 16-21, 1999

[51] Smith J.W., "Structural robustness analysis and the fast fracture analogy", Structural engineering international, 16(2), 118-123, 2006

[52] JZ Zhang, GQ Li, J Jiang. 2020. Dynamic effects on steel frames with concrete slabs under a sudden edge-column removal scenario, Journal of Structural Engineering; 146 (9), 04020185

[53] JZ Zhang, GQ Li, J Jiang, WJ Zhang. 2019. Collapse resistance of composite framedstructures considering effects of slab boundary restraints, Journal of Constructional Steel Research; 158, 171-181.

[54] GQ Li, JZ Zhang, J Jiang. 2020, Multi-storey composite framed-structures due to edgecolumn loss, Advanced Steel Construction; 16 (1), 20-29.

[55] GQ Li, JZ Zhang, J Jiang. 2020, Collapse resistance of steel frames with concrete slabs due to penultimate-side column loss, Advances in Structural Engineering, 23 (7), 1473-1486.

[56] Lu D.G. et al., "Robustness assessment for progressive collapse of framed structures using pushdown analysis methods", International Journal of Reliability and Safety, 6(1-3), 15-37, 2012.

[57] Jian Jiang, Qijie Zhang, Liulian Li, Wei Chen, Jihong Ye, Guo-Qiang Li. (2020) Review on Quantitative Measures of Robustness for Building Structures Against Disproportionate Collapse. International Journal of High-rise Buildings, 9(2): 159-186.

[58] Li G.Q., Li L.L., Jiang B.H. and Lu Y., "Experimental study on progressive collapse resistance of steel frames under a sudden column removal scenario", Journal of
Constructional Steel Research, 147, 1-15, 2018.

[59] Vlassis A. et al., "Progressive collapse of multi-storey buildings due to failed floor impact", Engineering Structures, 31(7), 1522-1534, 2009.

[60] Li L.L., Li G.Q., Jiang B.H. and Lu Y., "Analysis of robustness of steel frames against progressive collapse", Journal of Constructional Steel Research, 143, 264-278, 2018.

[61] Tsai M.H. and Lin B.H., "Dynamic amplification factor for progressive collapse resistance analysis of an RC building", The Structural Design of Tall and Special Buildings, 18(5), 539-557, 2009.

[62] Li G.Q., Zhang Y., Yang T.C., Jiang J., Lu Y. and Chen S.W., "Effects of Blast-induced Column Failure Pattern on Collapse Behavior of Steel Frames", Advanced Steel Construction, 14(3): 376-390, 2018.

[63] Jiang B., Li G.Q., Li L. and Izzuddin B., "Experimental studies on progressive collapse resistance of steel moment frames under localized furnace loading", Journal of Structural Engineering, DOI: 10.1061/(ASCE)ST.1943-541X.0001947, 2017.

[64] Jiang B., Li G.Q., Li L. and Izzuddin B., "Simulations on progressive collapse resistance of steel moment frames under localized fire", Journal of Constructional Steel Research, 138, 380-388, 2017.

[65] Zhang J.Z. and Li G.Q., "Collapse Resistance of Steel Beam-Concrete Slab Composite Substructures Subjected to Middle Column Loss", Journal of Constructional Steel Research, 145, 471-488, 2018.

[66] Li G.Q., Zhang J.Z. and Jian Jiang J., "Analytical modeling on collapse resistance of stee beam-concrete slab composite substructures subjected to side column loss", Engineering Structures, 169, 238-255, 2018.

[67] JZ Zhang, GQ Li, J Jiang, (2020), Collapse of steel-concrete composite frame under edgecolumn loss-Experiment and its analysis, Engineering Structures 209, 109951. 